\title{
Structural, Dielectric and Electrical Properties of Sol- Gel Auto-Combustion Technic of CuFeCr0.5Ni0.5O4 Ferrite
}

Omar Rejeiba ( $\square$ omarrejieba@yahoo.com )

ISSAT-Gabes\&FSTBZ sidi Bouzid

\section{Fakher Hcini}

FSTBZ -sidi Bouzid

Maria Nasri

FSTBZ sidi Bouzid

Bandar Alzahrani

Prince Sattam University

Mohamed Lamjed Bouazizi

Prince Sattam Univ

E. K. Hlil

INP Grenoble Alpes France

Jabeur Khelifi

FSTBZ sidi Bouzid

Kamel Khirouni

FSG gabes

Essebti Dhahri

FSS Sfax

\section{Research Article}

Keywords: Spinel ferrite, Activation energy, Modulus, Nyquist representation, relaxation phenomenon.

Posted Date: April 6th, 2021

DOl: https://doi.org/10.21203/rs.3.rs-384366/v1

License: (c) (i) This work is licensed under a Creative Commons Attribution 4.0 International License.

Read Full License 


\section{Structural, Dielectric and Electrical properties of Sol-gel auto- combustion technic of $\mathrm{CuFeCr}_{0.5} \mathrm{Ni}_{0.5} \mathrm{O}_{4}$ ferrite}

Omar Rejaiba ${ }^{1,2 *}$, Fakher Hcini ${ }^{1}$, Maria Nasri ${ }^{1}$, Bandar Alzahrani ${ }^{5}$, Mohamed Lamjed Bouazizi ${ }^{5}$, E. K. Hlil ${ }^{3}$, Jabeur Khelifi, ${ }^{1,}$, Kamel Khirouni, Essebti Dhahri ${ }^{4}$

${ }^{1}$ Research Unit of Valuation and Optimization of Resource, Faculty of Science and Technology of Sidi Bouzid, University of Kairouan, University Campus Agricultural City, 9100 Sidi Bouzid, Tunisia.

${ }^{2}$ Higher Institute of Applied Sciences and Technology of Gabes ISSAT, 6072 ,Uinversity of Gabes, - Tunisia.

${ }^{3}$ Univ. Grenoble Alpes, CNRS, Grenoble INP, Institut Néel, 38000 Grenoble, France.

${ }^{4}$ Laboratory of Applied Physics, Faculty of Sciences of Sfax, University of Sfax,3000 Sfax-Tunisia.

${ }^{5}$ Department of Mechanical Engineering, College of Engineering, Prince Sattam Bin Abdulaziz University, Alkharj 11942, Saudi Arabia.

\section{Abstract}

The $\mathrm{CuFeCr}_{0.5} \mathrm{Ni}_{0.5} \mathrm{O}_{4}$ (CFO) compound was synthesized using sol-gel reaction combustion technic. The structural analysis showed that the obtained composites have a polycrystalline nature and the cubic spinel structure ( $F d \overline{3} m$ space group). Microstructural analysis revealed the formation of spherical and elongated grains of our sample. The dielectric and electrical transport properties of $\mathrm{CuFeCr}_{0.5} \mathrm{Ni}_{0.5} \mathrm{O}_{4}$ were investigated in detail by $\mathrm{Ac}$ impedance spectroscopy in a wide range of temperature $(200 \mathrm{~K}-400 \mathrm{~K})$ and frequency $(100 \mathrm{~Hz}$ to100KHz). Our results show that the electrical modulus and impedance studies confirm the presence of a relaxation phenomenon with non-Debye type in the prepared sample. The activation energy $E_{\mathrm{dc}}$ estimated from the slope of the linear fit plot is equal to $0.158 \mathrm{eV}$ with frequency of $100 \mathrm{~Hz}$ and $0.126 \mathrm{eV}$ with frequency of $1 \mathrm{MHz}$ at temperature range $200 \mathrm{~K}-400 \mathrm{~K}$. Close activation energies values were found from analyzes of relaxation time and dcconductivity indicating that the relaxation and the conduction processes may be attributed to the presence of free carrier charges and impurities at the grain boundaries. The conduction process for samples is described by the NSPT model. The complex impedance analyses and modulus formalism confirm a grain and grain boundary mechanism contributing to the dielectric properties. The real and the imaginary parts of the impedance are well fitted to equivalent electrical circuit $\left(\mathrm{R}_{\mathrm{g}}+\mathrm{R}_{\mathrm{gb}} / / \mathrm{CPE} \mathrm{gb}\right)$ was used for modeling the Nyquist data.

Keywords: Spinel ferrite; Activation energy; Modulus; Nyquist representation; relaxation phenomenon.

Corresponding author: omarrejieba@yahoo.com my.bouazizi@psau.edu.sa (M.L.Bouazizi) 


\section{Introduction}

Nowadays, Spinel Ferrites (SF) ceramics has attracted large number of researchers due to their important and unusual physical-chemical properties of such device. A vast domains application in modern technology of the Spinel ferrite as; magnetic storage, precursors for Ferro-fluids, magnetic guided drug-delivery agents, biomedicine ,gas sensor, radio, television, microwave and satellite communication. Crystallographically, two main classes of cubic ferrites: spinel ferrites and garnet ferrites. The SF is divided into three types on the bases of sites' occupation: (a) normal spinel ferrites, (b) inverse spinel ferrites, and (c) mixed spinel ferrites $[1,2]$. Spinel ferrites characterized by low eddy currents and dielectric losses but they have a high electrical resistivity. Spinel Ferrites (SF) formula $\mathrm{AFe}_{2} \mathrm{O}_{4}$ where $\mathrm{A}=\mathrm{Mn}, \mathrm{Fe}, \mathrm{Co}$, $\mathrm{Ni}, \mathrm{Cu}$, and $\mathrm{Zn}$ is the divalent transition metal that can occupy either tetrahedral (A) or octahedral (B) sites or both the sites which surrounded by 4 and 6 oxygen ions respectively. Besides, the magnetic and dielectric proprieties can be affected and modified in Spinel Ferrites (SF) by the cations distributions over these available sites generated from the three principal kinds of super-exchange interactions A-B, A-A and B-B which are mediated by the intermediate $\mathrm{O}^{2-}$ ions $[3,4]$.Generally, the physical properties of spinel materials are controlled and investigated by the grain boundaries than by the grains. Several reports are available in the literature on magnetic and electrical proprieties of many Spinel Ferrites (SF) types was investigated nanocrystalline $\mathrm{NiFe}_{2} \mathrm{O}_{4}$ [5], $\mathrm{Ni} 0.65 \mathrm{Zn}_{0.35} \mathrm{Fe}_{2}-\mathrm{x} \mathrm{Mn}_{\mathrm{x}} \mathrm{O}_{4}$ [6], $\mathrm{Ni}_{\mathrm{x}} \mathrm{Co} 1-{ }_{\mathrm{x}} \mathrm{Fe}_{2} \mathrm{O}_{4}$ [7], spinel $\mathrm{MFe}_{2} \mathrm{O}_{4}(\mathrm{M}=\mathrm{Zn}, \mathrm{Cu}, \mathrm{Ni}$, and $\mathrm{Co})$ ferrite[8]. Among many ferrites, Spinel Ferrites (SF) attracts much attention due to their high coercivity, magneto-crystalline anisotropy, moderate saturation magnetization, wear resistance, electrical insulation, chemical and physical and thermal stability and high Curie temperature [9-11]. In this regard, spinel ferrites were prepared by a great number of methods: sol-gel [12, 13], hydrothermal [14], microemulsion [15], polyol [16], combustion [17], chemical co-precipitation [18, 19], solvothermal [20], solid-state method [21] and solution combustion [22-26].Each synthesis method, the structure and properties of the obtained device was controlled by the annealed temperature. So the magnetic and electrical properties of these ferrites type could be strongly influenced by fabrication methods steps, annealing temperature, structural properties such as grain size, porosity, crystallite size.

In the current research work is focused on investigating the effect of grain and grain boundary on the electrical and dielectric proprieties of $\mathrm{CuFeCr} 0.5 \mathrm{Ni}_{0.5} \mathrm{O}_{4}$ synthesized by solgel combustion process using electrical impedance technique. 


\section{Experimental procedure}

The $\mathrm{CuFeCr}_{0.5} \mathrm{Ni}_{0.5} \mathrm{O}_{4}$ ferrite is prepared by sol-gel method using the following precursors: $\mathrm{Cr}\left(\mathrm{NO}_{3}\right)_{2} .6 \mathrm{H}_{2} \mathrm{O}, \mathrm{Fe}\left(\mathrm{NO}_{3}\right)_{3} .9 \mathrm{H}_{2} \mathrm{O}$ and $\mathrm{Cu}\left(\mathrm{NO}_{3}\right)_{2} .3 \mathrm{H}_{2} \mathrm{O}$ with $99.9 \%$ purity and purchased from Sigma Aldrich. The initial solution was prepared by mixing distilled water and the nitrates followed by the addition of citric acid $\left(\mathrm{C}_{6} \mathrm{H}_{8} \mathrm{O}_{7}\right)$ as complexing agent for different metal ions. The solution was heated to $70^{\circ} \mathrm{C}$ with thermal agitation followed by the addition of ethylene glycol until a high viscosity residue (gel) is formed. Then, the obtained gel was heated on a hot plate at $180^{\circ} \mathrm{C}$ until dry foam was formed. This latter was grinded and then annealed at $400^{\circ} \mathrm{C}$ to evaporate the organic materials. The black obtained powder was calcined at $700^{\circ} \mathrm{C}$ for $24 \mathrm{~h}$ to ensure the complete release of the organic compounds. After annealing at $900^{\circ} \mathrm{C}$ the material undergoes another grinding and annealing cycles until the formation of a very fine powder to obtain the desired phase.

Homogeneity, phase purity and cell parameters were investigated using Philips X'Pert system. Morphology of the sample was observed by scanning electron microscope (SEM). For the electrical and dielectric measurements the parallel surfaces of pellets were painted with silver paint prior. Ac impedance spectroscopy type Agilent 4294A Network Analyzer in the $\mathrm{C}_{\mathrm{p}}-\mathrm{R}_{\mathrm{p}}$ configuration (capacitance in parallel with resistance) were used at various steady temperatures $(200 \mathrm{~K}-400 \mathrm{~K})$ in the frequency range of $100 \mathrm{~Hz}-100 \mathrm{KHz}$.

\section{Results and Discussions}

\subsection{Structural Properties}

Fig. 1 shows X-ray diffractogram (XRD) with Rietveld refinement of the synthesized $\mathrm{CuFeCr} 0.5 \mathrm{Ni}_{0.5} \mathrm{O}_{4}$ compound in the $2 \theta$ range of $15^{\circ}-70^{\circ}$ at room temperature. The patterns reveal good crystallinity with the presence of narrow and strong diffraction peaks. The presence of the strong diffraction peaks corresponding to the crystal planes (111), (220), (311), (222), (400), (422), (511) and (442) indicates the presence of cubic spinel phase. In $\mathrm{CuFeCr}{ }_{0.5} \mathrm{Ni}_{0.5} \mathrm{O}_{4}$ sample synthesized by sol-gel method the result indicates that the diffraction peaks are well defined and correspond in relative height to the peaks reported in the pattern, discarding preferential orientation. Further, the pattern exhibits a sharper and more intense peak which can be related to the higher crystallinity in $\mathrm{CuFeCr} 0.5 \mathrm{Ni}_{0.5} \mathrm{O}_{4}$ sample. In the Rietveld analysis using Fullprof program is shown, the positions of the different atoms were taken at $8 \mathrm{a}\left(\frac{1}{8}, \frac{1}{8}, \frac{1}{8}\right)$ for $\left(C u_{1}^{2+}\right)_{A}$ cations, $16 \mathrm{~d}\left(\frac{1}{2}, \frac{1}{2}, \frac{1}{2}\right)$ for $\left[C r_{0.5}^{2+} N i_{0.5}^{2+} F e_{1}^{3+}\right]_{B}$ cations, 
and $32 \mathrm{e}(\mathrm{x}, \mathrm{y}, \mathrm{z})$ for $\mathrm{O}$. The refined structural parameters are given in Table 1.The average crystallite size is obtained from XRD peaks using the Scherer formula as [27, 28]:

$$
D=\frac{K \lambda}{\beta \cos (\theta)}
$$

Where $\mathrm{K}=0.9, \lambda=1.541 \AA$ is the used wavelength of the $\mathrm{X}$-ray, $\beta$ is the corrected full-width half maxima of the XRD peaks (FWHM) and $\theta$ is the Bragg angle.

The estimated value of the average crystallite size is presented in Table 1 . The X-ray density of our sample was calculated according to the following equation [29-34]:

$$
D_{x}=\frac{8 M}{N_{A} a^{3}}
$$

Where $M$ is the molecular weight, $N_{A}$ is Avogadro's constant $\left(6.022 \times 10^{23} \mathrm{~mol}^{-1}\right)$, and " $a$ " is the lattice constant. The theoretical density was calculated using the following formula [3538]:

$$
D_{b}=\frac{m}{\pi r^{2} h}
$$

Here $m$ is the mass, $r$ and $h$ are respectively: the radius and the height of the sample. The difference between the X-ray density and the theoretical density sets forward the notion of porosity, which is calculated by the following formula [39-42]:

$$
P=\left(1-\frac{D_{b}}{D_{x}}\right) \times 100
$$

\subsection{Scanning electron microscopy}

The SEM micrographs in Fig. 2 show a uniform nanoparticle and almost spherical structural morphology with narrow size distribution. The specimens give grains morphology which some grains are necked in shape. This necking is attributed to the diffusion among the particles during sintering. Also, this is due to the fact that each particle observed by SEM consists of several crystallite domains. We notice that the diffusion means smaller particles join to form the larger one. Besides, micrographs show in homogeneous micro-particles with irregular shape. If the particles adhere together, agglomeration will be occurs which is due to the dipole-dipole interaction among the particles. Fig. 2-b depicts the grain number (counts) versus particle size $(\mu \mathrm{m})$. The size distribution of the sample was calculated using image $J$ 
software version 1.44p (USA).As observed, the histogram is well modeled by Gaussian fitting (Fig. 2-b). The estimated average grain size is about $0.790 \pm 0.2 \mu \mathrm{m}$, which is higher than the crystallite size previously determined from the Scherer formula.

\subsection{Dielectric and electrical study}

Dielectric properties of $\mathrm{CuFeCr} 0.5 \mathrm{Ni}_{0.5} \mathrm{O}_{4}$ ferrite materials strongly depend on the fabrication steps, composition, frequency and temperature. In order to investigate the electrical and dielectric characteristics of our spinel ferrites we used the impedances spectroscopy which provides valuable information about dynamic of charge carrier, conduction mechanism, dielectric relaxation and loss factor etc.

\subsubsection{Frequency and temperature dependence of ac conductivity $\left(\sigma_{a c}\right)$ :}

The study of frequency dependency of the ac conductivity $\left(\sigma_{\mathrm{ac}}\right)$ is an important implement to understand conduction mechanism and dynamic of charge carriers. The $\sigma_{\mathrm{ac}}$ curves versus frequency and for several temperature ranges are shown in Fig. 3. As can be seen from this plot, the conductivity shows two distinct regions within the measured frequency limits: (a) a plateau region and (b) a dispersion region. The plateau region corresponds to dc conductivity $\left(\sigma_{\mathrm{dc}}\right)$ at the low frequency range showing independence of frequency. This independence of frequency on conductivity spectra can be related to the insufficiencies magnitude of external applied field at low frequencies to initiate hopping conductivity. This is totally attributed to the long-range transport of charge carriers as a response to the applied signal field and also can be linked to the difference of response time carrier $(\tau)$ and applied frequency $(\omega=2 \pi f)$. Whereas, the dispersion region corresponds to conductivity at high frequency range and the value $\sigma$ was increased with increasing frequency. When temperature rises, a sufficient energy probably leads to the hopping of electron density increases between magnetic ions tetrahedral sites (A-sites) and B-sites which conduct to an increment of conductivity [43]. Besides, the ac conductivity corresponding to higher frequencies was caused by heating sample which lead to increase temperature and a higher energy need of the mechanism [44]. The frequency dependence of conductivity in CFO is formulated as the sum of these two parts and can be described according to Jonscher's power law as [45]:

$$
\sigma_{\text {tot }}=\sigma_{d c}+A \omega^{s}
$$


Here $\sigma_{\mathrm{dc}}$ represents the direct current conductivity, $A=\pi N^{2} e^{2} / 6 k T(2 \alpha)$ is a constant e is the electronic charge, $\mathrm{T}$ is the temperature, $\alpha$ is the polarizability of a pair of sites and $\mathrm{N}$ is the number of sites per unit volume among which hopping takes place $[46,47,48]$ and the exponent "s" represents the dimensionless frequency exponent representing the interaction between mobile ions the surrounding lattice [49]. The variation of "s" exponent with temperature refers to the polaron hopping; this variation was classified in three particular parts. Firstly, when "s" values vary between 0 and 1 with temperature, and it give us idea to understand the adequate theoretical model of conductivity mechanism. If $s=0$, the conductivity corresponds only to the dc conductivity $\sigma_{\mathrm{dc}}$. The third part when $\mathrm{s}$, is $0<\mathrm{s}<1$, the ac conductivity was indicated by jump mechanism. The variation of $\mathrm{s}$ with temperature dependence can be described by many several theoretical conduction models, if $\mathrm{s}$ is independent to temperature conduction mechanism is on concordance with the Quantum Tunneling model (QTM). If $\mathrm{s}$ increase with increasing temperature conductivity is described by Small Polaron model (SP). When the power s decrease with increasing temperature the conductivity was defined by Correlated Barrier Hopping $(\mathrm{CBH})$. And if s decrease with increasing temperature the conductivity is associated to the overlapping large polaron tunneling (OLPT) model $[50,51,52,53]$. To more understand the hopping mechanisms details, we use the power law given by Jonscher to fit the conductivity spectra [45].

Fig.4 depicts the s-T curve for $\mathrm{CuFeCr}_{0.5} \mathrm{Ni}_{0.5} \mathrm{O}_{4}$ ferrite. As was mentioned the $\mathrm{s}$ plot increase with temperature and the modeling of experimental plots shows an excellent agreement was observed between theoretical results and the experimental data of electrical conductivity. The value of the s exponent ranges between 0 and 1 and it vary from 0.6 to 0.7.According to the suggested model, the s-T behaviour indicating a non-overlapping small polaron tunnelling (NSPT) conduction process model is suitable to describe the conductionmechanism in the CFO spinel [54]. Furthermore, the obtained value of s indicated that the conduction process in the sample corresponds to the localized electron hopping model. Referring to Elliot and Hen [55], the increase of the exponent's' in this spinel ferrite is related to the high concentration of the free carriers. Using the hopping model, the binding energy $\mathrm{W}_{\mathrm{m}}$ can be calculated basing the followed relation [55]:

$$
S=1+\frac{4 k_{B} T}{W_{M}-k_{B} \log \left(\omega \tau_{0}\right)}
$$


After approximation and for large values of $\frac{W_{M}}{k_{B} T}$, the exponent equation will be simplified as following:

$s=1+\frac{4 k_{B} T}{W_{m}}$

where $k_{\mathrm{B}}$ is the Boltzmann constant, and the $W_{m}$ parameter represents the polaron binding energy .The determination value of the bonding energy of the carrier in its localized sites $W_{m}$ basing to Eq. 7 and using the slope of the s-T plots (see Fig.5 -a). So, $W_{m}$ is close to 0.425 $\mathrm{eV}$, this value of $W_{m}$ is in good agreement with the increase of the conductivity with temperature.

In other hand, at low frequency conductivity plots indicate that our spinel ferrite exhibits a semiconductor behavior in all temperature range. The dc conductivity $\sigma_{\mathrm{dc}}$ is well fitted basing to the Mottand Davis law which describes small polaron hopping [56]:

$\sigma_{d c} T=\sigma_{0} \exp \left(-\frac{E_{d c}}{k_{B} T}\right)$

Where $\sigma_{0}$ is a pre-exponential factor and $E_{d c}$ is the activation energy required in the samples. To calculate the $E_{d c}$ values Eq. (8) is being used by plotting the graph of $\log \left(\sigma_{d c} \times T\right)$ vs. $\left(\frac{1000}{T}\right)$ in Fig.5-b, 5-c.

The $E_{d c}$ value obtained from the slope of the linear fit curve for $\mathrm{CuFeCr}_{0.5} \mathrm{Ni}_{0.5} \mathrm{O}_{4}$ is equal to $0.158 \mathrm{eV}$ at $100 \mathrm{~Hz}$ and $0.126 \mathrm{eV}$ for $1 \mathrm{MHz}$. This values are comparable to other results in ferrite materials. Moreover, the values of activation energies are less than those found for other ferrite materials $[57,58]$, permitting to suggest that $\mathrm{CuFeCr} 0.5 \mathrm{Ni}_{0.5} \mathrm{O}_{4}$ sample are good conductors.

\subsection{Dielectric study}

The imaginary part of permittivity $\left(\varepsilon^{\prime \prime}\right)$ and loss factor $(\tan \delta)$ vs. frequency and temperature is presented in Fig.6 and 7. The dielectric losses have different origins: vibration losses, dipole losses and losses by conduction. Fig.6 illustrates the plot of loss factor tan $\delta$ versus frequency at studied temperature range for $\mathrm{CuFeCr} 0.5 \mathrm{Ni} 0.5 \mathrm{O}_{4}$ ferrite compound. The magnitude of $\tan \delta$ is very important at low frequency and decreases with increasing frequency. This high magnitude of $\tan \delta$ associated to the minimum value of conductivity 
which attributed to the high resistivity of grain boundaries at low frequency range. Consequently, the electron exchanges between magnetic ions require more energy leading to high value of energy loss. Whereas at the high frequency region, a small energy loss and high value of conductivity obtained electron hopping between magnetic ions need small amount of energy to make transfer mechanism. As one seen that the loss factor tan $\delta$ spectra increases with increasing temperature due to the increased conduction of thermally activated electrons $[59,44]$.

Fig. 7 displays the frequency dependence of imaginary dielectric part ( $\operatorname{Ln}(\varepsilon ")$ vs $\operatorname{Ln}$ $(\omega))$ at exploited temperatures range for $\mathrm{CuFeCr}_{0.5} \mathrm{Ni}_{0.5} \mathrm{O}_{4}$ ferrite pellet. As can be noticed at high frequency the $\varepsilon$ " $\square$ decrease with increasing frequency was explained by the decreases of polarization dipoles number under applied electric field [60-62]. Means, minority carrier (electron) in hopping process cannot fellow ac signal for certain frequency value. The determination of the polarization in ferrites is imposed by the direction of the applied field which leads to local displacement of the electrons between magnetic ions. However, at low frequency the existence of oxygen vacancies, grain boundaries traps, $\mathrm{Fe}^{2+}$ ions etc.[63] generate a high value of imaginary part $\varepsilon "$.In addition, imaginary part $\varepsilon$ " increase with temperature rise which activate thermally carrier for hopping process which confirms the semiconductor comportment of our sample . Furthermore, permittivity $\varepsilon$ " can be analyzed by the Giuntini theory [64] (the linear fit Fig. 7) which has been successfully applied to many materials such as; manganites, perovskites, and spinel ferrites [63, 65, 66]. Basing to the Giuntini model, the imaginary part of permittivity $\varepsilon$ " is given by the following expression [64]:

$\varepsilon^{\prime \prime}(\omega)=\left(\varepsilon_{0}-\varepsilon_{\infty}\right) 2 \pi^{2} N\left(\frac{n e}{\varepsilon_{0}}\right)^{3} K T \tau_{0}^{n} W_{M}^{-4} \omega^{m}$

Here $\varepsilon_{0}$ and $\varepsilon_{\infty}$ are respectively the static and optical dielectric constants, $N$ is the concentration localized states on sites, $m$ is the number of charge carriers able to cross the potential barrier, $\tau_{0}$ is the relaxation time, and $W_{M}$ is the maximum of energy required for the electrons to jump over barrier height (the energy required to move the electron from a site to the infinity).

The simplified Giuntini expression from Eq.9 can be rewritten as:

$\varepsilon^{\prime \prime}(\omega)=B(T) \omega^{m}$ 
Here $\mathrm{B}(\mathrm{T})$ is a constant dependent only on temperature and the $\mathrm{m}$ is given by $m=\frac{-4 k_{B} T}{W_{M}}$ which designated the exponent describing the interaction between electric dipoles. $\mathrm{W}_{M}$ is the energy necessary for charge carriers to jump above the potential barrier. So, to determine $\mathrm{W}_{\mathrm{M}}$ values, inset Fig.7 we illustrate the fit of $(\operatorname{Ln}(\varepsilon \square)$ vs $\operatorname{Ln}(\omega))$ spectra using Eq.10, the obtained values of $W_{M}$ is found to be $0.218 \mathrm{eV}$ for $\mathrm{CuFeCr}{ }_{0.5} \mathrm{Ni}_{0.5} \mathrm{O}_{4}$. We noticed, an increasing of $\mathrm{W}_{\mathrm{M}}$ with increasing temperature and the same behavior of $\mathrm{m}-\mathrm{T}$ curve which can be correlated to the disorder on our compound [67].

\subsection{Impedance analysis}

Fig. 8 depicts the evolution curves of the imaginary part of the normalized impedance $\mathrm{Z}$ " (i.e. $\frac{Z^{\prime \prime}}{Z^{\prime \prime}{ }_{\max }} \operatorname{vs} \log \left(\frac{f}{f_{\max }}\right)$ for the sample $\mathrm{CuFeCr}_{0.5 \mathrm{Ni} 0.5} \mathrm{O}_{4}$. It is clear that at low value of $\log \left(\frac{f}{f_{\max }}\right)$ the normalized impedance Z" spectra show dispersion with decreasing the temperature and rise to a maximum value for all curves while at high value of $\log \left(\frac{f}{f_{\max }}\right)$ all curves of Z" are entangled and overlapped on one single curve showing that the relaxation time dynamics is independent to the increases of temperature[68]. This result confirms that relaxations time distributions depend strongly to temperature effects [44].

In order to obtain exactly if the relaxation frequencies value of $Z$ ", we calculated $d\left(\frac{Z^{\prime \prime}}{Z^{\prime \prime}}\right) / d f$ and at $\mathrm{T}=260 \mathrm{~K}$ we plotted in Fig. 9 the evolution of $Z^{\prime \prime} / Z^{\prime \prime}{ }_{\max }$ and $d\left(\frac{Z^{\prime \prime}}{\left.Z^{\prime \prime}\right)_{\max }}\right) / d f$ versus $f / f_{\max }$ for $\mathrm{CuFeCr}_{0.5} \mathrm{Ni}_{0.5} \mathrm{O}_{4}$ nanoparticles. As one seen from this plots that the relaxation frequency show a clearly shift between the position of the maximum of the normalized impedance spectrum and its derivative which confirms the mechanism of non-Debye nature 
for our sample [69].So, it should be noted that relaxation mechanism show a good agreement for carrier charge type with temperature, means at high temperature the mechanism was governed by defects whereas at low temperature charge carrier predominate $[70,71]$.

Impedance spectroscopy is a reach and a powerful practical technic which make possible to understand clearly the relation between electrical proprieties and microstructure of CFO ferrites, grains and grain boundaries effects. In fact, the variation of the imaginary part of the impedance Z" as a function of the real part Z' of the compound $\mathrm{CuFeCr} 0.5 \mathrm{Ni}_{0.5} \mathrm{O}_{4}$ is represented in the form of impedance diagrams in the complex plane (Nyquist diagrams), at $\mathrm{T}$ $=300 \mathrm{~K}$ as illustrated on Fig. 10 .

It is clear from this figure that the impedance spectrum is characterized by the appearance of semi-circular arcs. The diameter of the semi-circle is limited by the total resistance of the material. The appearance of a single semi-circle for each temperature means that the electrical process obeys a single dipole relaxation [72]. Indeed, the analysis of the dielectric relaxation related to the grain boundaries for $\mathrm{T}=300 \mathrm{~K}$ has shown that conduction is controlled by grain boundaries which explains the appearance of a single semicircle in the Nyquist diagram.

The experimental data of this semicircle were well adjusted by the ZView software $[73,74]$ and the correct fit (red lines in Fig. 10) is obtained when using an equivalent circuit formed by a grain resistance $R_{g}$ in series with a parallel combination of a grain boundary resistance $R_{g b}$ and $C P E_{g b}$ represents the constant grain boundary phase element. Using an electrical circuit as follows $\left(R_{g}+R_{g b} / / C P E_{g b}\right)$ (see inset in Fig. 10) [75]. As shown in inset in Fig. 10, the impedance response of a constant phase element $(C P E)$ little to be given by the following relation [76].

$$
Z_{C P E}=\frac{1}{Q(j \omega)^{\alpha}}
$$

Where, $Q$ and $\alpha$ are the $C P E$ parameters which are frequency independent. The $R_{g}, R_{g b}, Q$ and $\alpha$ parameters were evaluated for the temperature $\mathrm{T}=300 \mathrm{~K}$ is regrouped in Fig.10. In fact, the resistance of the grains $R_{g}$ being very low by contribution to the resistance of the grain boundaries, which means that the conduction process in the prepared sample is mainly 
related to the contribution of the grain boundaries. It appears that with the increase in temperature the effect of grain boundaries facilitates the passage of charge carriers by lowering the barrier thus opening the way to an increase in electrical transport.

\subsection{Electrical modulus}

The real $\left(M^{\prime}\right)$ and imaginary $\left(M^{\prime \prime}\right)$ parts of the electrical modulus of our $\mathrm{CuFeCr} 0.5 \mathrm{Ni}_{0.5} \mathrm{O}_{4}$ ferrite were given from the real $\left(\varepsilon^{\prime}\right)$ and imaginary $\left(\varepsilon^{\prime \prime}\right)$ parts of the permittivity as follows [57]:

$$
\begin{aligned}
& M^{\prime}=\frac{\varepsilon^{\prime}}{\left(\varepsilon^{\prime 2}+\varepsilon^{\prime 2}\right)} \\
& M^{\prime \prime}=\frac{\varepsilon^{\prime \prime}}{\left(\varepsilon^{\prime 2}+\varepsilon^{\prime 2}\right)}
\end{aligned}
$$

Fig. 11 show the behavior of the real part of the modulus $\left(M^{\prime}\right)$ as a function of frequency and at different temperature. We note that the values of $\left(M^{\prime}\right)$ are very small in the low frequency region. This confirms that the polarization of the electrode makes a negligible contribution in the material [68]. As the frequency increases, the values of $\mathrm{M}^{\prime}$ continue to increase reaching saturation at high frequencies especially at low temperatures. This behavior may be due to the short distance mobility of charge carriers [78].

Fig. 12, represent the variation of the imaginary component of the electric modulus ( $M$ ') versus frequency for studied temperatures range of the ferrite $\mathrm{Cr}_{0.5} \mathrm{Ni}_{0.5} \mathrm{FeCuO}_{4}$. The $M$ "' $(f)$ spectra is characterized by well resolved peaks appearing at characteristic frequencies $\left(f_{M^{\prime \prime}}^{\max }\right)$, for different temperatures and the positions of these peaks shift to higher frequencies with increasing temperature. This behavior suggests that the relaxation time for this process increases with increasing temperature due to thermal activation of charge carriers. The $M$ ' ' $(f)$ curves were analyzed using the function of Kohlrausch, Williams and Watts $(K W W)[75,79]$ :

$$
M "=\frac{M_{1 \max }^{\prime \prime}}{\left(\left(1-\beta_{1}\right)+\left(\frac{\beta_{1}}{1+\beta_{1}}\right)\left[\left(\left(\frac{f_{1 \max }}{f}\right)+\left(\frac{f}{f_{1 \max }}\right)^{\beta_{1}}\right)\right]\right.}+\frac{M^{\prime \prime 2 \max }}{\left(\left(1-\beta_{2}\right)+\left(\frac{\beta_{2}}{1+\beta_{2}}\right)\left[\left(\left(\frac{f_{2 \max }}{f}\right)+\left(\frac{f}{f_{2 \max }}\right)^{\beta_{2}}\right)\right]\right.}
$$

Where $M_{\text {max }}^{\prime \prime}$ is the peak maxima and $f_{\max }$ its corresponding frequency, $\beta_{1}$ and $\beta_{2}$ are the stretching factors which rank between 0 and 1 [75, 79]. The plots of $M^{\prime \prime}(f)$ was well fitted using equation Eq.(13) (see Fig. 12). The values of $\beta_{1}$ and $\beta_{2}$ were found to be inferior to 1 and increase with increasing temperature. The variation of $\beta_{1}$ as a function of temperature was shown in Fig. 13. Therefore, this variation confirms the non-Debye dielectric behavior of the $\mathrm{Cr}_{0.5 \mathrm{Ni} 0.5 \mathrm{FeCuO}}$ ferrite [29]. N. Sivakumar et al [80] considered that the increase of $\beta_{1}$ and $\beta_{2}$ values with sintering temperature was linked to the rise of grain size on fabrication steps. On 
the other hand, the relaxation time $(\tau)$ was calculated from the relaxation frequency $\left(f_{\max }\right)$ through the following relation:

$$
\tau=\frac{1}{2 \pi f_{\max }}
$$

$\tau_{M^{n}}=\tau_{0} e^{\left(\frac{E_{M^{\prime \prime}}}{k_{B} T}\right)}$

with $\tau_{0}$ is a pre-exponential factor, $E_{M^{\prime \prime}}$ is the activation energy and $k_{B}$ is the Boltzmann constant.The linear fit of the curve using equation Eq.(15) allowed us to estimate the value of the activation energy as $\left(E_{M^{\prime \prime}}\right)=0.13 \mathrm{eV}$ for the sample $\mathrm{CuFeCr}{ }_{0.5} \mathrm{Ni}_{0.5} \mathrm{O}_{4}$. This value is very close to that deduced from the study of continuous conductivity which indicates that the relaxation and conduction processes can be attributed to the same type of charge carriers

\section{Conclusion}

$\mathrm{CuFeCr}_{0.5} \mathrm{Ni}_{0.5} \mathrm{O}_{4}$ spinel ferrite was prepared by sol-gel auto-combustion method. The $\mathrm{X}$-ray and SEM analysis revealed that our sample was single-phased with a cubic spinel structure. Electrical properties were investigated by impedance spectroscopy analysis in wide temperature and frequency ranges. Both complex modulus $\left(\mathrm{M}^{*}\right)$ and complex impedance $\left(\mathrm{Z}^{*}\right)$ analyses suggested the presence of the non-Debye type in spinel ferrite sample. Complex modulus plots suggested the presence of grain as well as grain boundary contributions in our pellets. Also, the conduction process for samples is described by the NSPT model. From relaxation time and $\sigma_{\mathrm{dc}}$-conductivity we found close activation energies. Our analysis of Nyquist diagram by an equivalent electrical circuit reveals that the conduction process in the samples is due to the grain boundary contribution. At low frequency regime, the values of $\varepsilon$ " and $\tan \delta$ are higher, showing that the synthesized material is a suitable candidate for low frequency energy storage devices with good electrical proprieties.

\section{Acknowledgements}

**This project was supported by the Deanship of Scientific Research at Prince Sattam Bin Abdulaziz University under the research project No 2020/01/16565.**

\section{$\underline{\text { References }}$}


[1]B.B.V.S. Vara Prasad, K.V. Ramesh, A. Srinivas, Structural and magnetic studies on CoZn nanoferritesynthesized via sol-gel and combustion methods, Materials Science-Poland, 37(1), 2019, pp. 39-54. DOI: 10.2478/msp-2019-0013

[2] Shoyeb Mohamad F.Shaikh, Mohd Ubaidullah, Rajaram S.Mane, Abdullah M.Al-Enizi ,Chapter 4 - Types, Synthesis methods and applications of ferrites .Spinel Ferrite.Nanostructures for Energy Storage Devices,Micro and Nano Technologies 2020, Pages 51-82 https://doi.org/10.1016/B978-0-12-819237-5.00004-3

[3] M. T. Rahman, M. Vargas, C.V. Ramana, "Structural characteristics, electrical conduction and dielectric properties of gadolinium substituted cobalt ferrite, J. Alloys Compd. 617 (2014) 547-562.http://dx.doi.org/10.1016/i.jallcom.2014.07.182

[4] Y.Y. Meng, Z.W. Liu, H.C. Dai, H.Y. Yu, D.C. Zeng, S. Shukla, R. V. Ramanujan, Structure and magnetic properties of $\mathrm{Mn}(\mathrm{Zn}) \mathrm{Fe}_{2}{ }_{-} \mathrm{RE}_{x} \mathrm{O}_{4}$ ferrite nano-powders synthesized by co-precipitation and refluxing method, J. Powd. Tech. 229 (2012) 270-275. https://doi.org/10.1016/j.powtec.2012.06.050

[5]N Ponpandian , P Balaya and A Narayanasamy,Electrical conductivity and dielectric behaviour of nanocrystalline NiFe2O4 spinel,J. Phys.: Condens. Matter 14 (2002) 3221-3237 DOI: $10.1088 / 0953-8984 / 14 / 12 / 311$

[6]Gerald F. Dionne and Russell G. West, Magnetic and dielectric properties of the spinel ferrite system $\mathrm{Ni}_{0.65} \mathrm{Zn}_{0.35} \mathrm{Fe}_{2}-\mathrm{x}_{\mathrm{x}} \mathrm{Mn}_{4}$,Journal of Applied Physics 61, 3868 (1987); doi: $\underline{10.1063 / 1.338623}$

[7] V.L. Mathe ,R.B. Kamble, Electrical and dielectric properties of nanocrystalline Ni-Co spinel ferritesMaterialsResearchBulletin48 (2013) $1415-1419$ http://reserved.http://dx.doi.org/10.1016/j.materresbull.2012.12.019

[8] E. Ranjith Kumar, S.P. Reddy, G. Sarala Devi, S.Sathiyaraj,Structural, dielectric and gas sensing behavior ofMn substituted spinel MFe2O4 (M= Zn, CU, NI, and CO) ferrite nanoparticles, Journal of Magnetism and Magnetic Materials.398( 2016) 281-288DOI: http://dx.doi.org/10.1016/j.jmmm.2015.09.018

[9] M. Cernea, P. Galizia, I. Ciuchi, G. Aldica, V. Mihalache, L. Diamandescu, C. Galassi, $\mathrm{CoFe} 2 \mathrm{O} 4 m a g n e t i c$ ceramic derived from gel and densified by spark plasma sintering, $\mathrm{J}$. Alloys Compd., 656 (2016) 854-862.

[10] P.C. Rajath, R.S. Manna, D. Banerjee, M.R. Varma, K.G. Suresh, A.K. Nigam, Magnetic properties of $\mathrm{CoFe} 2 \mathrm{O} 4$ synthesized by solid state, citrate precursor and polymerized complex 
methods: A comparative study,J. Alloys Compd. 453, 298-303 (2008) https://doi.org/10.1016/j.jallcom.2006.11.058

[11]N. Spaldin, «Magnetic Materials: Fundamentals and Device Applications〉 Cambridge University Press,Cambridge, (2003)

[12]M. Houshiar, F. Zebhi, Z. J. Razi, A. Alidoust, and Z. Askari, "Synthesis of cobalt ferrite (CoFe2O4) nanoparticles using combustion, coprecipitation, and precipitation methods: A comparison study of size, structural, and magnetic properties," Journal of Magnetism and Magnetic Materials, vol. 371, pp. 43-48, 2014. https://doi.org/10.1016/j.jmmm.2014.06.059

[13]A. Pradeep, P. Priyadharsini, and G. Chandrasekaran, "Sol-gel route of synthesis of nanoparticles of $\mathrm{MgFe} 2 \mathrm{O} 4$ and XRD, FTIR and VSM study," Journal of Magnetism and $\begin{array}{llllllll}\text { Magnetic } & \text { Materials, } & \text { vol. } 32008 .\end{array}$ https://doi.org/10.1016/j.jmmm.2008.06.012

[14]L. Wang, J. Li, Y. Wang, L. Zhao, and Q. Jiang, “Adsorption capability for Congo red on nanocrystalline $\mathrm{MFe} 2 \mathrm{O} 4(\mathrm{M}=\mathrm{Mn}, \mathrm{Fe}, \mathrm{Co}, \mathrm{Ni})$ spinel ferrites," Chemical Engineering Journal, vol. 181-182, pp. 72-79, 2012. https://doi.org/10.1016/j.cej.2011.10.088

[15]V. Pillai and D. O. Shah, "Synthesis of high-coercivity cobalt ferrite particles using water-in-oil microemulsions," Journal of Magnetism and Magnetic Materials, 163,pp. 243248, 1996. https://doi.org/10.1016/S0304-8853(96)00280-6

[16]J. Wagner, T. Autenrieth, and R. Hempelmann, "Core shell particles consisting of cobalt ferrite and silica as model ferrofluids [CoFe2O4-SiO2 core shell particles]," Journal of Magnetism and Magnetic Materials, vol. 252, pp. 4-6, 2002. https://doi.org/10.1016/S0304$\underline{8853(02) 00729-1}$

[17]S. Ammar, A. Helfen, N. Jouini et al., "Magnetic properties of ultrafine cobalt ferrite particles synthesized by hydrolysis in a polyol medium," Journal of Materials Chemistry, vol. 11, no. 1, pp. 186-192, 2001. https://doi.org/10.1039/B003193N

[18]R. Ianoş, M. Bosca, and R. Lazău, "Fine tuning of $\mathrm{CoFe} 2 \mathrm{O} 4$ properties prepared by solution combustion synthesis," Ceramics International, vol. 40, no. 7, pp. 10223-10229, 2014. https://doi.org/10.1016/j.ceramint.2014.02.110 
[19]U. Salazar-Kuri, J.O. Estevez, N.R. Silva-González, U. Pal, Large magnetostriction in chemically fabricated $\mathrm{CoFe} 2 \mathrm{O} 4$ nanoparticles and its temperature dependence. J. Magn. Magn. Mater. 2018, 460, 141-145. https://doi.org/10.1016/j.jmmm.2018.03.074

[20] P. Annie Vinosha, S. Jerome Das, Investigation on the role of $\mathrm{pH}$ for the structural, optical and magnetic properties of cobalt ferrite nanoparticles and its effect on the photofenton activity. Mater. Today Proc. 2018, 5, 8662-8671. https://doi.org/10.1016/j.matpr.2017.12.291

[21] N. Dong, F. He, J. Xin, Q. Wang, Z. Lei, B. Su, Preparation of CoFe2O4 magnetic fiber nanomaterial via a template-assisted solvothermal method. Mater. Lett. 2015, 141, 238241. https://doi.org/10.1016/j.matlet.2014.11.054

[22] P.C.R.Varma, R.S. Manna, D. Banerjee, M.R.Varma, K.G.Suresh, A.K. Nigam, Magnetic properties of $\mathrm{CoFe} 2 \mathrm{O} 4$ synthesized by solid state, citrate precursor and polymerized complex methods: A comparativestudy. J. Alloys Compd. 2008, 453, 298-303. https://doi.org/10.1016/j.jallcom.2006.11.058

[23] A. Maleki, N. Hosseini, A. Taherizadeh, Synthesis and characterization of cobalt ferrite nanoparticles prepared by the glycine-nitrate process. Ceram. Int. 2018, 44, 8576-8581. https://doi.org/10.1016/j.ceramint.2018.02.063

[24] M.A. Gabal, A.A. Al-Juaid, S. El-Rashed, M.A. Hussein, Synthesis and characterization of nano-sized CoFe2O4 via facile methods: A comparative study. Mater. Res. Bull. 2017, 89, 68-78. https://doi.org/10.1016/j.materresbull.2016.12.048

[25] B. Pourgol mohammad, S.M. Masoudpanah, M.R. Aboutalebi, Synthesis of CoFe2O4 powders with highsurface area by solution combustion method: Effect of fuel content and cobalt precursor. Ceram. Int. 2017, 43,3797-3803. https://doi.org/10.1016/j.ceramint.2016.12.027

[26] D. Rajan Babu, K. Venkatesan, Synthesis of nanophasic CoFe2O4 powder by selfigniting solution combustionmethod using mix up fuels. J. Cryst. Growth 2017, 468, 179-184. https://doi.org/10.1016/j.jcrysgro.2016.11.054

[27] Walmir E. Pottkera, Rodrigo Onoa, Miguel Angel Cobosb, Antonio Hernandob,c,Jefferson F.D.F. Araujod, Antonio C.O. Brunod, Sidney A. Lourençoa, Elson Longoe,Felipe A. La Portaa, Influence of order-disorder effects on the magnetic and optical 
properties of NiFe 2 O 4 nanoparticles, Ceramics International.44(2018)17290-17297. https://doi.org/10.1016/j.ceramint.2018.06.190

[28]B.D. Cullity , S.R. Stock . Elements of X-Ray Diffraction, 3rd edn. Upper Saddle River, NJ: Prentice Hall; 2001.

[29] S. Hcini, A. Omri ,M.Boudard ,M. L .Bouazizi ,A. Dhahri ,K.Touileb ,Effect of sintering temperature on structural, magnetic, magnetocaloric and critical behaviors of $\mathrm{Ni}-\mathrm{Cd}-\mathrm{Zn}$ ferrites prepared using sol-gel method, J. of Mag. and Mag. Mat.464 (2018) 91-102. https://doi.org/10.1016/j.jmmm.2018.05.045

[30] K.M. Batoo, M.S.A. El-sadek, Electrical and magnetic transport properties of $\mathrm{Ni}-\mathrm{Cu}-\mathrm{Mg}$ ferrite nanoparticles prepared by sol-gel method,J. Alloy. Compd. 566(2013)112-119. https://doi.org/10.1016/j.jallcom.2013.02.129

[31] D.H. Kim, D.E. Nikles, D.T. Johnson, C.S. Brazel, Heat generation of aqueously dispersed $\mathrm{CoFe} 2 \mathrm{O} 4$ nanoparticles as heating agents for magnetically activated drug delivery and hyperthermia. J. Magn. Magn. Mater. 320(2008) 2390-2396. DOI:10.1016/j.jmmm.2008.05.023

[32] N.M. Deraz, Effects of magnesia addition on structural, morphological and magnetic properties of nano-crystalline nickel ferrite system. Ceram. Int. 38(2012) 511-516. DOI: $\underline{10.1016 / j . c e r a m i n t .2011 .07 .036}$

[33] M. R. Ahmad, Y. Jamil, A. Tabasuum, T. Hussain, Refinement in the structural and magnetic properties of $\mathrm{Co} 0.5 \mathrm{Ni} 0.5 \mathrm{Fe} 2 \mathrm{O} 4$ and its application as lasermicro-propellant using ablation confinement. J.Magn. Magn. Mater. 384(2015)302-307. DOI: 10.1016/j.jmmm.2015.02.064

[34] G.V.Duong, N. Hanh, D.V. Linh, R. Groessinger, P.Weinberger, E. Schafler, M. Zehetbauer, Monodispersed nanocrystalline $\mathrm{Co} 1 \square \mathrm{xZnxFe} 2 \mathrm{O} 4$ particles by forced hydrolysis: Synthesis and characterization. J. Magn. Magn. Mater. 311(2007) 46-50. DOI: 10.1016/j.jmmm.2006.11.167

[35] V. Sepelak, I. Bergmann, A. Feldhoff, P. Heitjans, F. Krumeich, D. Menzel, F.J. Litterst, S.J.Campbell, K.D. Becker, Nanocrystalline Nickel Ferrite, NiFe2O4: Mechanosynthesis, Nonequilibrium Cation Distribution, Canted Spin Arrangement, and Magnetic Behavior. J. Phys. Chem. C 111(2007) 5026-5033. https://doi.org/10.1021/jp067620s

[36] Y. Slimani, H. Güngüness, M. Nawaz, A. Manikandan, H.S. el Sayed, M.A. Almessiere, H. Sözeri, S.E. Shirsath, I. Ercan, A. Baykal, Magneto-optical and microstructural properties 
of spinel cubic copper ferrites with Li-Al co-substitution. Ceram. Int. 44(2018) 14242-14250. https://doi.org/10.1016/j.ceramint.2018.05.028

[37] J.M.D. Coey, Noncollinear spin arrangement in ultrafine ferrimagnetic crystallites. Phys. Rev. Lett. 27(1971)1140-1142. https://doi.org/10.1103/PhysRevLett.27.1140

[38] M. Amir, H. Gungunes, Y. Slimani, N. Tashkandi, H.S. el Sayed, F. Aldakheel, M. Sertkol, H. Sozeri, A. Manikandan, I. Ercan, et al. Mossbauer studies and magnetic properties of cubic CuFe2O4 nanoparticles. J. Supercond. Nov. Magn. 32(2018)557-564. DOI https://doi.org/10.1007/s10948-018-4733-5

[39] M. A. Ahmed, E. Ateia, SI. El-Dek, Rare earth doping effect on the structural and electrical

properties of Mg-Ti ferrite, Mater. Lett. 57 (2003) 4256-4266. https://doi.org/10.1016/S0167$\underline{577 X(03) 00300-8}$

[40] N. Rezlescu, E. Rezlescu, C. Pasnicu, M. L. Craus, Effects of the rare-earth ions on some properties of a nickel-zinc ferrite, J. Phys. Codens. Matter, 6 (1994)5707. https://doi.org/10.1088/0953-8984/6/29/013

[41] M.A. Elkestawy, AC conductivity and dielectric properties of, $\mathrm{Zn} 1-\mathrm{xCuxCr} 0.8 \mathrm{Fe} 1.2 \mathrm{O} 4$ spinel ferrites, J. All and Com 492 (2010) 616-620 https://doi.org/10.1016/j.jallcom.2009.11.194

[42] Abdul Samee Fawzi, A.D. Sheikh, V.L. Mathe, Structural, dielectric properties and AC conductivity of Ni(1-x)ZnxFe2O4 spinel ferrites, J. All and Com 502 (2010) 231-237 [43] J.S. Ghodake, R.C. Kambale, S.V. Salvi , et al. Electric properties of Co substituted NiZn ferrites. J Alloys Comp.2009;486:830-834.

[44] A. Selmi, S. Hcini, H. Rahmouni, A. Omri, M. Lamjed Bouazizi \& A. Dhahri,Synthesis, structural and complex impedancespectroscopy studies of $\mathrm{Ni} 0.4 \mathrm{Co} 0.4 \mathrm{Mg} 0.2 \mathrm{Fe} 2 \mathrm{O} 4$ spinel ferrite, PHASE TRANSITIONS.90 (2017)942-954 http://dx.doi.org/10.1080/01411594.2017.1309403

[45] A.K. Jonscher, The Universal dielectric response. Nature. 1977;267:673-679. https://doi.org/10.1038/267673a0

[46] K AMAR NATH, K PRASAD, K P CHANDRA and A R KULKARNI, Impedance and a.c. conductivity studies of $\mathrm{Ba}(\operatorname{Pr} 1 / 2 \mathrm{Nb} 1 / 2$ ) $\mathrm{O} 3$ ceramic, Bull. Mater. Sci., Vol. 36, No. 4, (2013) 591-599 DOI: 10.1007/s12034-013-0503-y 
[47]Amal M. Abdel - Karim, A.H. Salama, Fatma A. El - Samahy ,Mervat El - Sedik, Fayez H. Osman, Some dielectric properties of novel nano - s - triazine derivatives, J Phys Org Chem30:e3703.( 2017)1-9. DOI: 10.1002/poc.3703

[48]SKS Parashar, Swarat Chaudhuri, Satyendra Narayan Singh \& Mahmood Ghoranneviss ,Electrical conduction in nanoceramic PGT synthesised by high energy ball milling, Journal of Theoretical and Applied Physics7, 26 (2013)1-20. https://doi.org/10.1186/2251-7235-7-26 [49] D.K. Pradhan , B. Behera, P.R..Das, Studies of dielectric and electrical properties of a new type of complex tungsten bronze electroceramics. J Mater Sci Mater Electron. 2012;23:779. https://doi.org/10.1007/s10854-011-0492-9

[50] T.Ş. Kuru, E. Şentürk, V. Eyüpoğlu,Overlapping Large Polaron Conductivity Mechanism and Dielectric Properties of A10.2Cd0.8Fe2O4 Ferrite Nanocomposite ,J. Supercond. Nov. Magn. 30,655-674 (2017). https://doi.org/10.1007/s10948-016-3847-x

[51]R. Megha, Y.T. Ravikiran, S.C. Vijaya Kumari, S. Thomas, Optimized polyanilinetransition metal oxide composites: A comparative study of alternating current conductivity via correlated barrier hopping model ,Appl.Phys. A-Mater. 123(245), 1-10 (2017). https://doi.org/10.1002/pc.24375

[52] D.K. Rana, S.K. Singh, S.K. Kundu, R.J. Choudhary, S. Basu,Electrical and magnetic properties of polyvinyl alcohol-cobalt ferrite nanocomposite films,Bull. Mater. Sci. 41, 92 (2018).https://doi.org/10.1007/s12034-018-1608-0

[53] A.K. Pradhan, S. Saha, T.K. Nath,AC and DC electrical conductivity, dielectric and magnetic properties of $\mathrm{Co} 0.65 \mathrm{Zn} 0.35 \mathrm{Fe} 2-\mathrm{x}$ Mo x O4 $(\mathrm{x}=0.0,0.1$ and 0.2$)$ ferrites ,Appl. Phys. A-Mater. 123, 715(2017). https://doi.org/10.1007/s00339-017-1329-z

[54] A. Sutka, S. Lagzdina, G. Mezinskis, A. Pludons, I. Vitina, L. Timma,A comparative study of $\mathrm{Ni} 0.7 \mathrm{Zn} 0.3 \mathrm{Fe} 2 \mathrm{O} 4$ obtained by sol-gel auto-combustion and flash combustion methods ,IOP Conf. Ser.: Mater. Sci. Eng. 25 (2011) 012019-8. DOI: 10.1088/1757$\underline{899 X / 25 / 1 / 012019}$

[55] S.R. Elliot, F.E.G. Henn,Application of the Anderson-Stuart model to the AC conduction of ionically conducting materials ,J. Non-Cryst. Solids 32 (1990) 179-190. https://doi.org/10.1016/0022-3093(90)90691-E

[56] N.F. Mott, E.A. Davis 〈Electronic processes in non crystalline materials〉 Oxford: Clarendon Press; 1979 
[57] F. Hcini, S. Hcini, B. Alzahrani, S. Zemni, M.L. Bouazizi, Effect of Cr substitution on structural, magnetic and impedance spectroscopic properties of $\mathrm{Cd} 0.5 \mathrm{Zn} 0.5 \mathrm{Fe} 2-\mathrm{xCrxO} 4$ ferrites, Applied Physics A 126 (2020) 362.DOI https://doi.org/10.1007/s00339-020-03544-Z [58] S. Hcini, A. Omri, M. Boudard, M.L. Bouazizi, A. Dhahri, K. Touileb, Microstructural, magnetic and electrical properties ofZn0.4M0.3Co0.3Fe2O4 $(\mathrm{M}=\mathrm{Ni}$ and $\mathrm{Cu})$ ferrites synthesized by sol-gel method ,J Mater Sci: Mater. Electron. 29 (2018) 6879-6891.DOI https://doi.org/10.1007/s10854-018-8674-3

[59] A.M.M. Farea , S. Kumar , K.M. Batoo, Structure and electrical properties of Co0.5CdxFe2.5;xO4 ferrites. J AlloyCompd. 464(2008)361-369. https://doi.org/10.1016/j.jallcom.2007.09.126

[60] E. Oumezzine, S. Hcini, F.I.H. Rhouma, M. Oumezzine, Frequency and temperature dependence of conductance, impedance and electrical modulus studies of Ni0.6Cu0.4Fe2O4 $\begin{array}{lllll}\text { spinel ferrite,J. } & \text { Alloys } & \text { Compd. } & 726 & \text { (2017) }\end{array}$ https://doi.org/10.1016/j.jallcom.2017.07.298

[61] S.E.L. Kossi, F.I.H. Rhouma, J. Dhahri, K. Khirouni, Structural and electric properties of La0.7 $\mathrm{Sr}_{0.25} \mathrm{Na}_{0.05} \mathrm{Mn}_{0.9} \mathrm{Ti}_{0.1} \mathrm{O}_{3}$. ceramics. Phys. B 440, 118-123 (2014). https://doi.org/10. 751 1016/j.physb.2014.01.016

[62] A. Shukla, R.N.P. Choudhary., A. K. Thakur,Thermal, structural and complex impedance analysis of Mn4+ modified BaTiO3 electroceramic ,J. Phys. Chem. Solid. 70 (2009) 14011407 https://doi.org/10.1016/j.jpcs.2009.08.015

[63]R. Mguedla, A. Ben Jazia, M. Saadi, K. Khirouni, N. Chniba-boudjada, andW. Boujelben, Structural, electrical, dielectric and optical properties of $\mathrm{PrCrO} 3$ ortho-chromite,J. Alloys Compd. 812(2020)152130-11. https://doi.org/10.1016/j.jallcom.2019.152130

[64] J.C. Giuntini, J.V. Zanchetta, D. Jullien, R. Eholie, P. Houenou,Temperature dependence of dielectric losses in chalcogenide glasses ,J. Non-Cryst. Solids 45 (1981) 57-62. https://doi.org/10.1016/0022-3093(81)90089-2

[65] A. Ben Jazia Kharrat, M. Bourouina, N. Moutia, K. Khirouni, W. Boujelben, Gd doping effect on impedance spectroscopy properties of sol-gel prepared Pr0.5-

xGdxSr0.5MnO3 (0x0.3) perovskites, J. Alloy. Comp. 741 (2018) 723-733. https://doi.org/10.1016/j.jallcom.2018.01.236

[66] M. Ben Bechir, K. Karoui, M. Tabellout, K. Guidara, A. Ben Rhaiem, Electric and 
dielectric studies of the $[\mathrm{N}(\mathrm{CH} 3) 3 \mathrm{H}] 2 \mathrm{CuCl} 4$ compound at low temperature, J. Alloy. Comp. 588 (2014) 551-557. https://doi.org/10.1016/j.jallcom.2013.11.141

[67]W. Ncib, A. B. J. Kharrat, M. A. Wederni, K. Khirouni, and W. Boujelben, J. Alloys Compd. 768, 249 (2018). DOI: 10.1016/j.jallcom.2018.07.192

[68]E. Oumezzine, S. Hcini , F.I.H. Rhouma, et al. Frequency and temperature dependence of conductance, impedanceand electrical modulus studies of $\mathrm{Ni0} .6 \mathrm{Cu} 0.4 \mathrm{Fe} 2 \mathrm{O} 4$ spinel ferrite. J Alloys Compd.2017;726:187. DOI:10.1016/j.jallcom.2017.07.298

[69] S. Hcini, S. Khadhraoui, A. Triki, S. Zemni, M. Boudard and M. Oumezzine,Impedance Spectroscopy Properties of Pr0.67A0.33MnO3 (A = Ba or Sr) Perovskites ;J. Supercond.Nov. Magn. 27 (2014) 195-201.DOI https://doi.org/10.1007/s10948-013-2240-2

[70] H. E. Sekrafi, A. Ben Jazia Kharrat, M. A. Wederni, N. Chniba-Boudjada, K. Khirouni, W. Boujelben,Impact of low titanium concentration on the structural, electrical and dielectric properties of $\mathrm{Pr} 0.75 \mathrm{Bi} 0.05 \mathrm{Sr} 0.1 \mathrm{Ba} 0.1 \mathrm{Mn} 1-\mathrm{xTixO} 3(\mathrm{x}=0,0.04)$ compounds, Journal of Materials Science: Materials in Electronics. 30(2019)876-891.https://doi.org/10.1007/s10854$\underline{018-0359-4}$

[71] K.S. Cole, R.H. Cole,Dispersion and Absorption in Dielectrics I. Alternating Current Characteristics ,Chem. Phys. 9(1941)341-351 http://dx.doi.org/10.1063/1.1750906

[72] N.H. Vasoya, P.K. Jha, K.G. Saija, S.N. Dolia, K.B. Zankat, K.B. Modi,Electric Modulus, Scaling and Modeling of Dielectric Properties for Mn2+-Si4+ Co-substituted MnZn Ferrites ,J. Electron. Mater. 45 (2016) 917-927.DOI: https://doi.org/10.1007/s11664-015$\underline{4224-4}$

[73] A. Dutta,S. Saha, T. P. Sinha, Dielectric relaxation and electronic structure of $\mathrm{Ca}\left(\mathrm{Fe}_{1 / 2} \mathrm{Sb}_{1 / 2}\right) \mathrm{O}_{3}$ Phys. Rev. B65 (2007) 155113-7 DOI: 10.1103/PhysRevB.76.155113

[74] D. Johnson 〈ZView: a software program for IES analysis〉 Version 2.8. Southern Pines, NC: Scribner Associates, Inc.; 2008.

[75] C.B. Mohamed, K. Karoui, S. Saidi, K Guidara, A.B. Rhaiem,Electrical properties, phase transitions and conduction mechanisms of the $[(\mathrm{C} 2 \mathrm{H} 5) \mathrm{NH} 3] 2 \mathrm{CdCl} 4$ compound, Physica B 451 (2014) 87-95. https://doi.org/10.1016/j.physb.2014.06.006 
[76] S. Hcini, S. Khadhraoui, A. Triki, S. Zemni, M. Boudard and M. Oumezzine,Impedance Spectroscopy Properties of Pr0.67A0.33MnO3 (A = Ba or Sr) Perovskites ;J. Supercond. Nov. Magn. 27 (2014) 195-201.DOI https://doi.org/10.1007/s10948-013-2240-2

[77] S.E.L. Kossi, F.I.H. Rhouma, J. Dhahri, K. Khirouni, Structural and electric properties of La0.7Sr0.25Na0.05Mn0.9Ti0.1O3. ceramics. Phys. B 440, 118-123 (2014). https://doi.org/10. $\underline{751 \text { 1016/j.physb.2014.01.016 }}$

[78] A. Shukla, R.N.P. Choudhary., A. K. Thakur,Thermal, structural and complex impedance analysis of Mn4+ modified BaTiO3 electroceramic ,J. Phys. Chem. Solid. 70 (2009) 14011407 https://doi.org/10.1016/j.jpcs.2009.08.015

[79] N.H. Vasoya, P.K. Jha, K.G. Saija, S.N. Dolia, K.B. Zankat, K.B. Modi,Electric Modulus, Scaling and Modeling of Dielectric Properties for Mn2+-Si4+ Co-substituted MnZn Ferrites ,J. Electron. Mater. 45 (2016) 917-927.DOI: https://doi.org/10.1007/s11664-015$\underline{4224-4}$

[80] N. Sivakumar, A. Narayanasamy, N. Ponpandian, G. Govindaraj, Grain size effect on the dielectric behavior of nanostructured Ni0.5Zn0.5Fe2O4J. Appl. Phys. 101, 084116 (2007) https://doi.org/10.1063/1.2721379

\section{Figures Captions}

Fig. 1: X-ray diffraction pattern with Rietveld refinement for $\mathrm{CuFeCr} 0.5 \mathrm{Ni} 0.5 \mathrm{O} 4$ ferrite. All peaks are indexed in the $F d \overline{3 m}$ space group. The difference between the XRD pattern (red) and calculated curve (black) is presented by the bottom line (green), and the blue lines represents the Bragg positions.

Fig.2: Histograms of the grain size distribution. The inset contains the SEM image for our $\mathrm{CuFeCr} 0.5 \mathrm{Ni} 0.5 \mathrm{O} 4$ ferrite.

Fig.3: Total conductivity variation versus frequency at different temperatures for

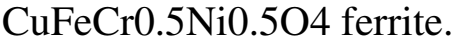

Fig.4: Typical example fitted using the universal Jonscher power law. The inset shows the variation of the exponent s vs. temperature for $\mathrm{CuFeCr} 0.5 \mathrm{Ni} 0.5 \mathrm{O} 4$. 
Fig.5: $\log \left(\sigma_{d c} \times T\right)$ vs. $(1000 / \mathrm{T})$ at(b) $100 \mathrm{~Hz}$ and (c) $1 \mathrm{MHz}$. Red solid lines represent the linear fit to the experimental data

Fig.6: Frequency dependence at different temperatures of loss factor ( $\tan \delta)$ for $\mathrm{CuFeCr} 0.5 \mathrm{Ni0} .5 \mathrm{O} 4$.

Fig.7: Frequency dependence at different temperatures of the imaginary part of permittivity for $\mathrm{CuFeCr} 0.5 \mathrm{Ni} 0.5 \mathrm{O} 4$. Red solid lines represent the fit according to Giuntini equation. The insets show the temperature dependence of the parameter $\mathrm{m}$.

Fig.8: Scaling behavior of $Z^{\prime \prime}$ curves at various temperatures for $\mathrm{CuFeCr0.5Ni0.5O4.d} \mathrm{(}$

Fig.9: Frequency evolution of $d\left(\frac{Z^{\prime \prime}}{Z^{\prime \prime}{ }_{\max }}\right) / d f$ and $Z^{\prime \prime} / Z_{\text {max }}$ at $\mathrm{T}=260 \mathrm{~K}$ for $\mathrm{CuFeCr}_{0.5} \mathrm{Ni}_{0.5} \mathrm{O}_{4}$.

Fig.10: Complex impedance spectra for fitting using Zview software. Inset: the appropriate equivalent electrical circuit.

Fig.11: Frequency dependence at different temperatures of real part ( $\left.\mathrm{M}^{\prime}\right)$ of electrical modulus for $\mathrm{CuFeCr} 0.5 \mathrm{Ni} 0.5 \mathrm{O} 4$.

Fig.12: Frequency dependence at different temperatures of imaginary part (M") of electrical modulus for $\mathrm{CuFeCr} 0.5 \mathrm{Ni} 0.5 \mathrm{O} 4$. Red solid lines represent the fitting to the experimental data of M"(f) using KWW function

Fig.13: Variation of $\beta 1$ vs. temperature for $\mathrm{Cr} 0.5 \mathrm{Ni} 0.5 \mathrm{FeCuO} 4$.

Fig.14: The $\log \left(\tau_{M^{\prime \prime}}\right)$ versus $(1000 / \mathrm{T})$. Red solid line is the linear fit for $\mathrm{Cr}_{0.5} \mathrm{Ni}_{0.5} \mathrm{FeCuO}_{4}$.

\section{Table Captions}

Table1: Structural parameters for $\mathrm{CuFeCr} 0.5 \mathrm{Ni} 0.5 \mathrm{O} 4$ ferrite obtained following the structural refinement by Rietveld method. a: cell parameter; V: cell volume; Biso: isotropic thermal agitation parameter; $\mathrm{x}, \mathrm{y}$ and $\mathrm{z}$ : atomic positions; RA distance $(\mathrm{Cu}-\mathrm{O})$; $\mathrm{RB}$ distance $(\mathrm{Ni}, \mathrm{Cr}$, $\mathrm{Fe}-\mathrm{O}$ ); $\theta \mathrm{A}-\mathrm{O}-\mathrm{B}$ : angle (Cu- O- Ni, Cr, Fe); $\theta \mathrm{B}-\mathrm{O}-\mathrm{B}$ : angle (Ni, $\mathrm{Cr}, \mathrm{Fe}-\mathrm{O}-\mathrm{Ni}, \mathrm{Cr}, \mathrm{Fe}$ ); Gs: average grains size; Dx: XRD density; Db: theoretical density. Agreement factors of profile 
Rp, weighted profile Rwp, and structure RF. $\chi 2$ : the goodness of fit. The numbers in parentheses are estimated standard deviations to the last significant digit. 
Figures

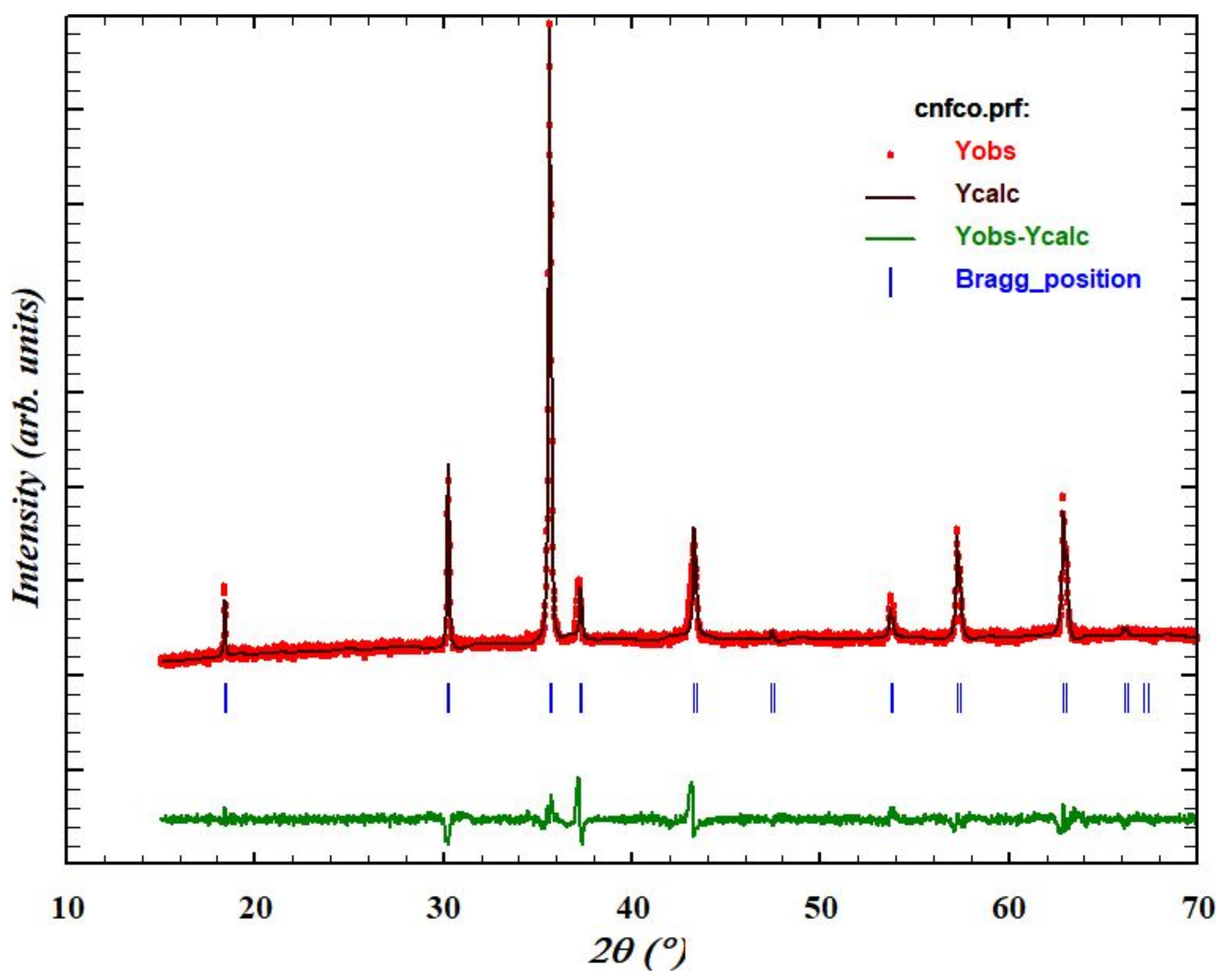

Figure 1

X-ray diffraction pattern with Rietveld refinement for CuFeCr0.5Ni0.504 ferrite. All peaks are indexed in

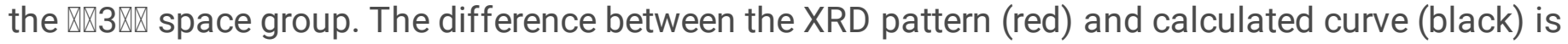
presented by the bottom line (green), and the blue lines represents the Bragg positions. 


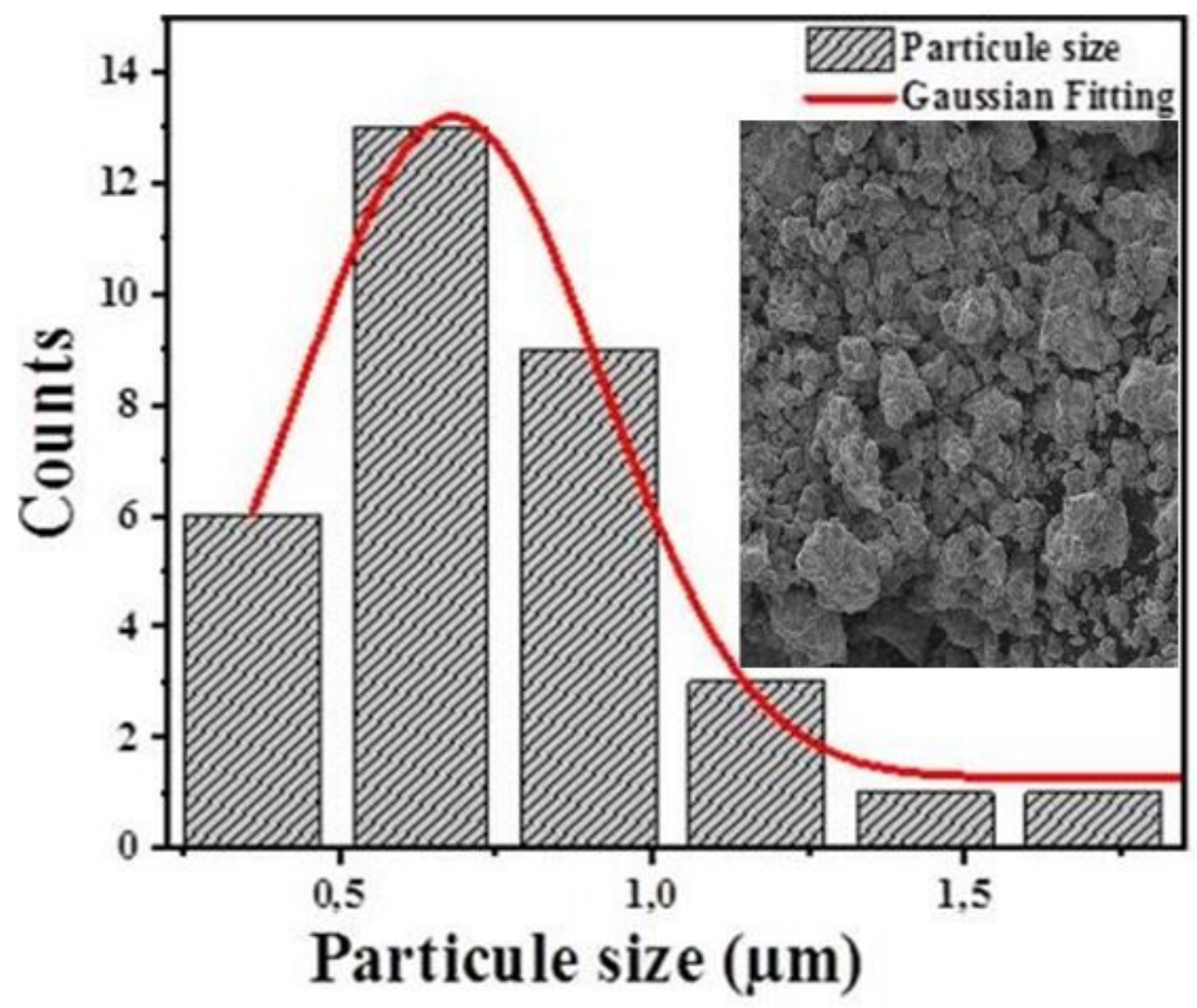

Figure 2

Histograms of the grain size distribution. The inset contains the SEM image for our CuFeCr0.5Ni0.5O4 ferrite. 


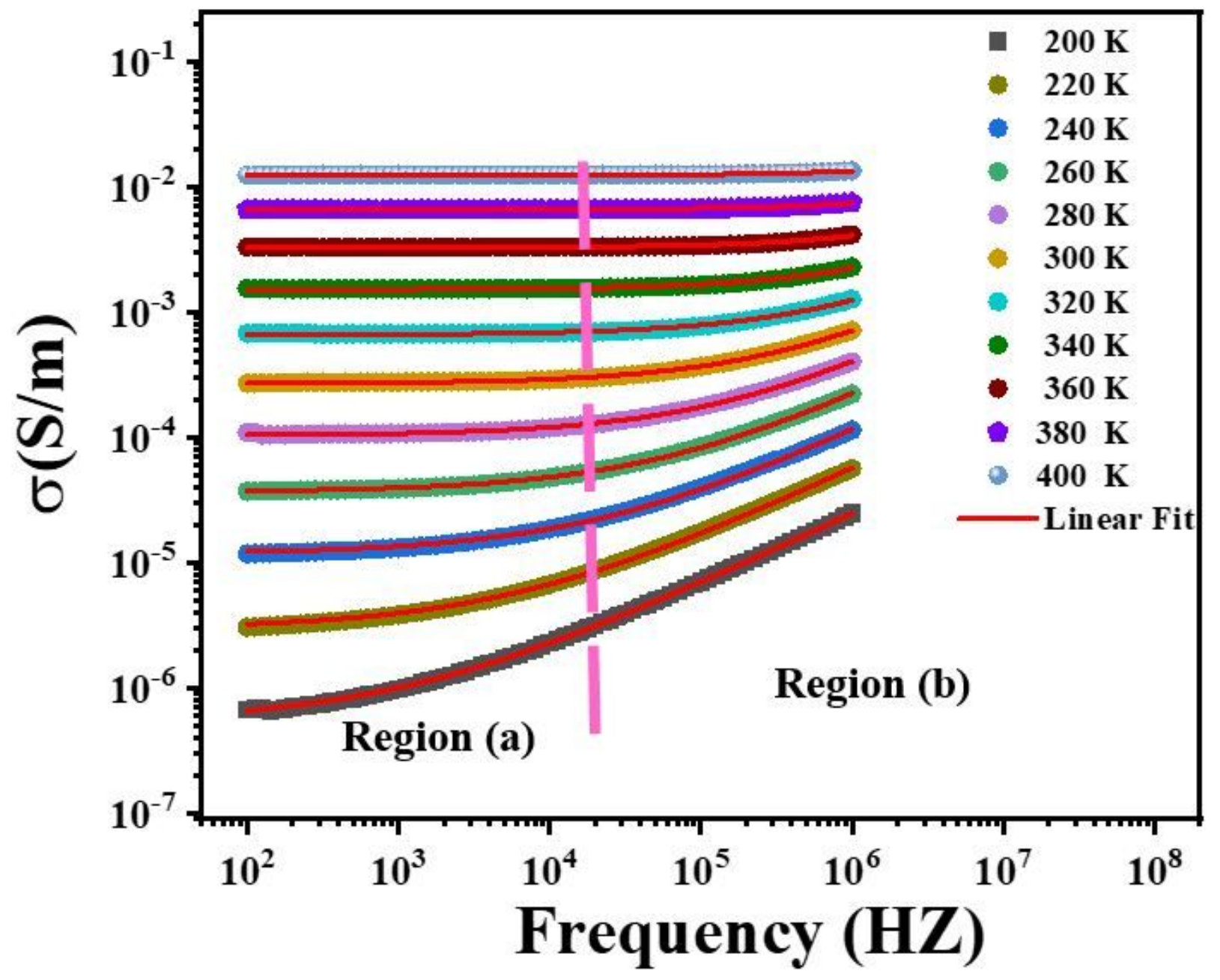

Figure 3

Total conductivity variation versus frequency at different temperatures for CuFeCr0.5Ni0.504 ferrite. 


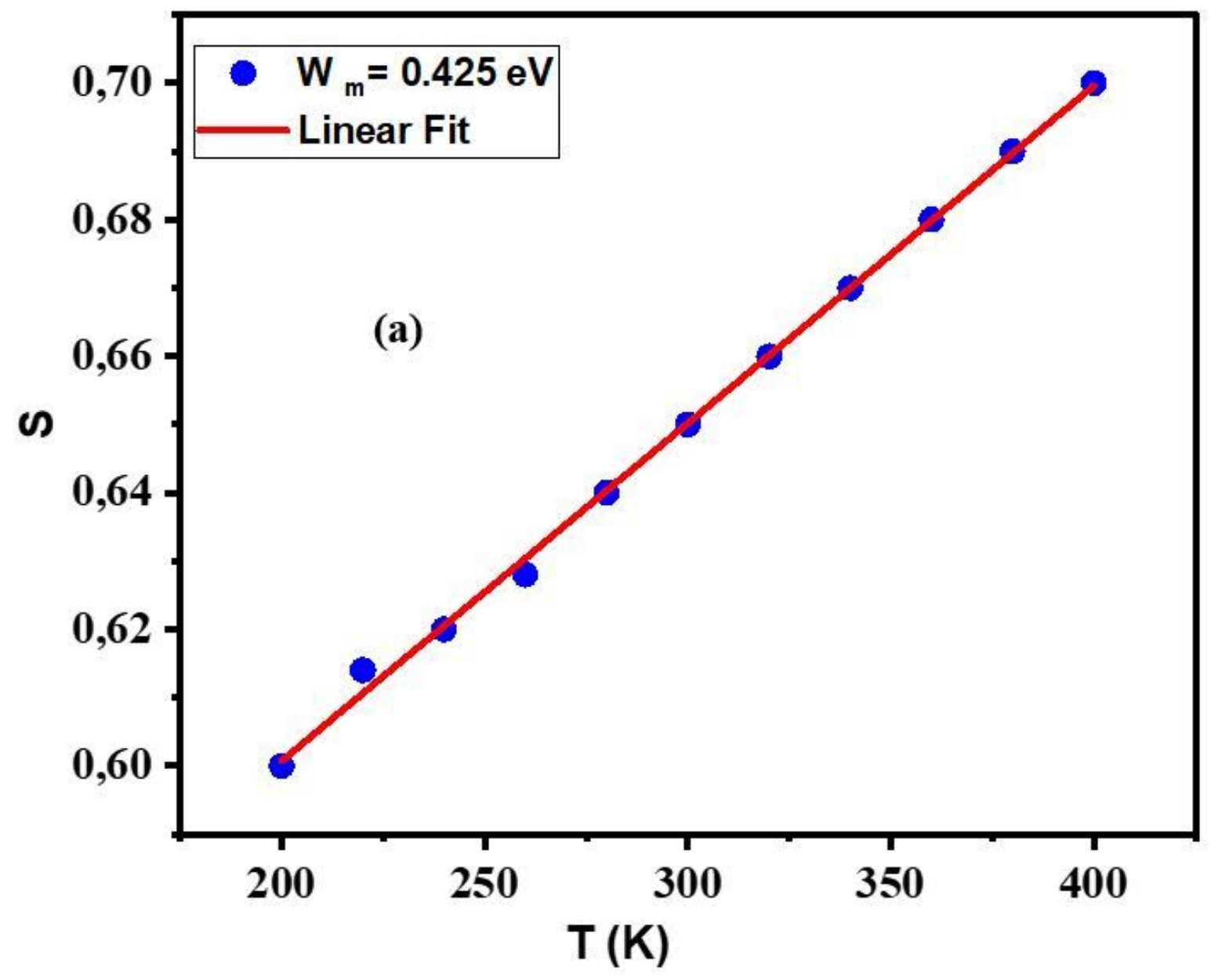

Figure 4

Typical example fitted using the universal Jonscher power law. The inset shows the variation of the exponent s vs. temperature for CuFeCr0.5Ni0.504 . 

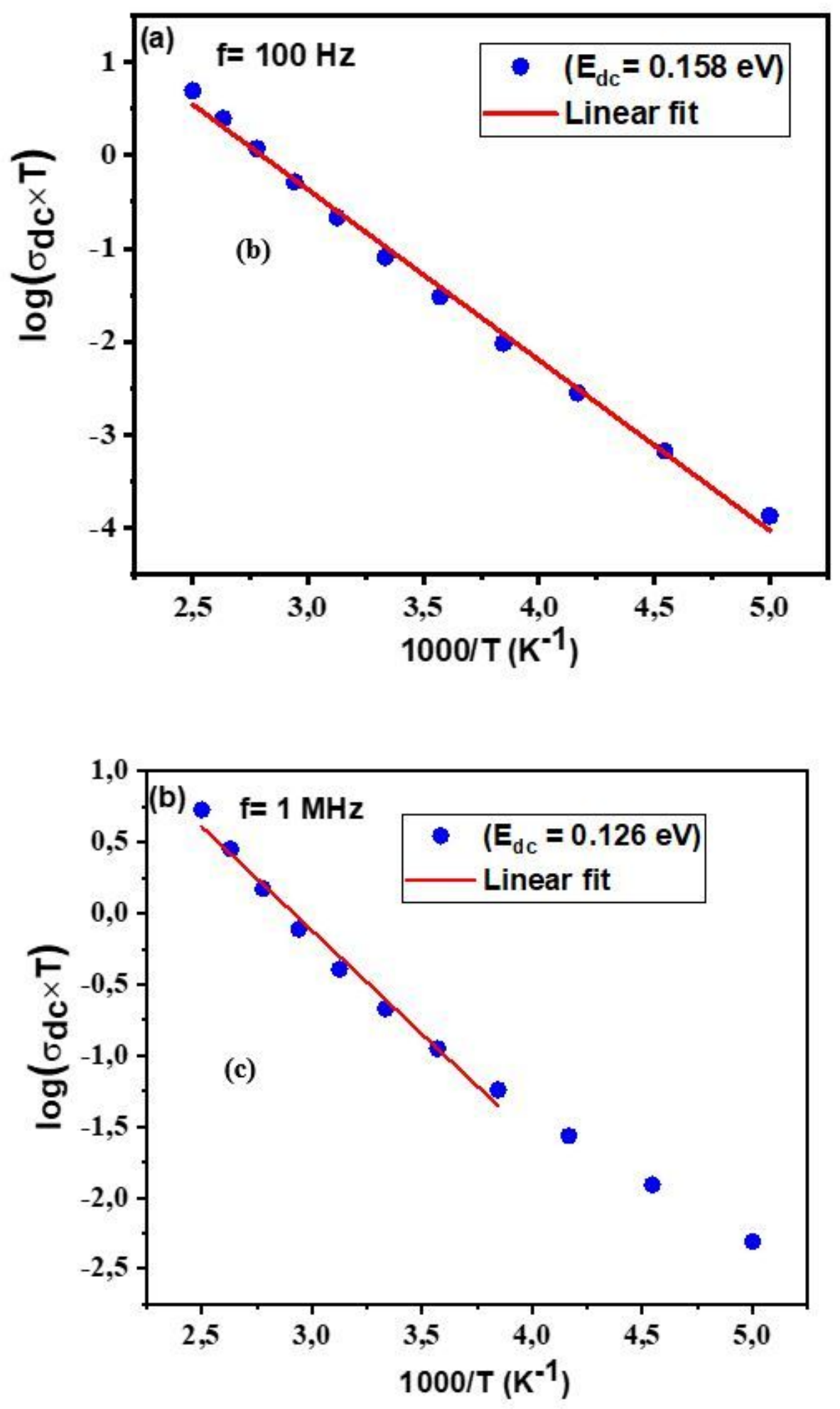

Figure 5

$\log (\sigma d c \times T)$ vs. $(1000 / \mathrm{T})$ at(b) $100 \mathrm{~Hz}$ and (c) $1 \mathrm{MHz}$. Red solid lines represent the linear fit to the experimental data 


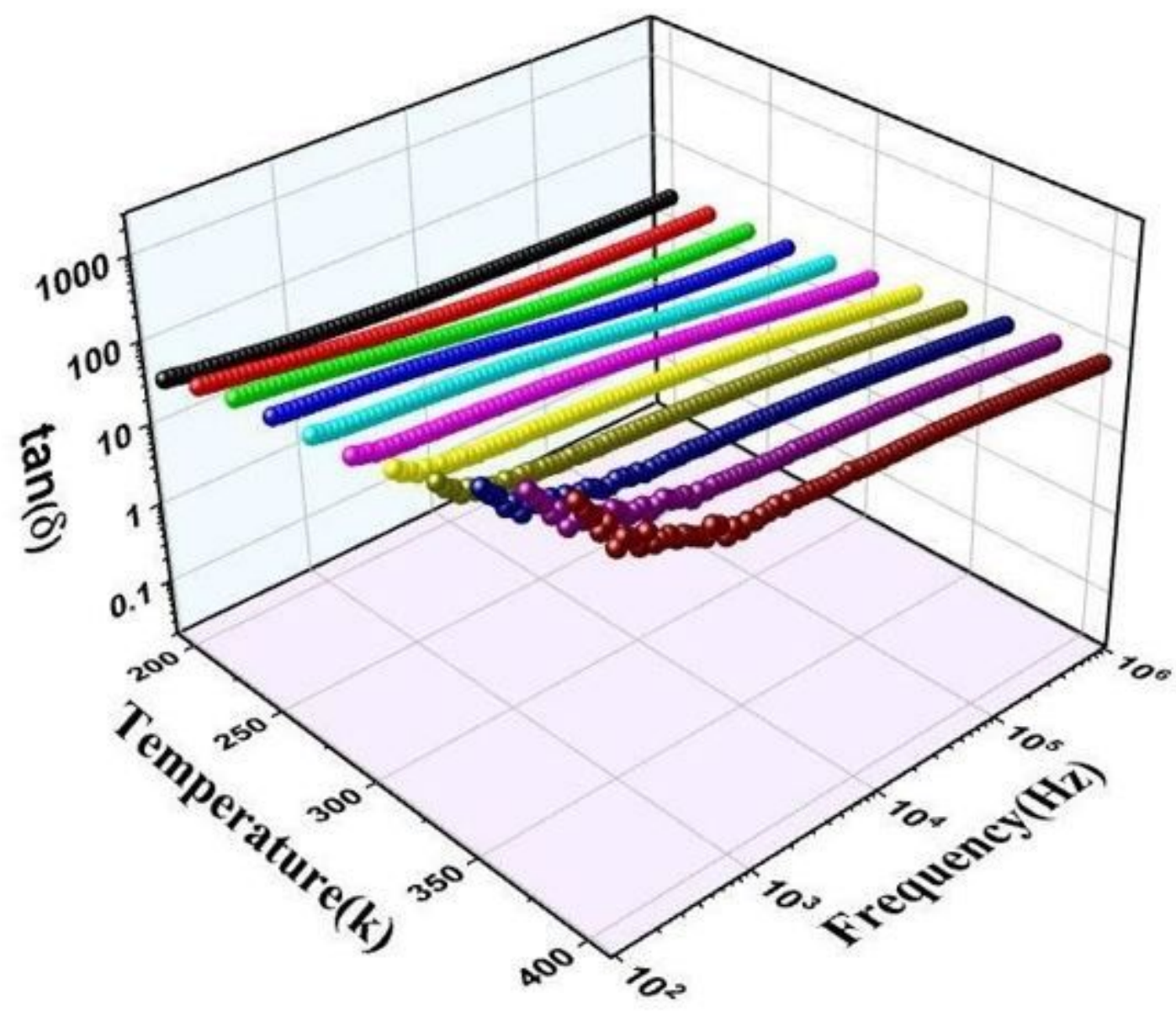

Figure 6

Frequency dependence at different temperatures of loss factor (tanס) for CuFeCr0.5Ni0.504. 


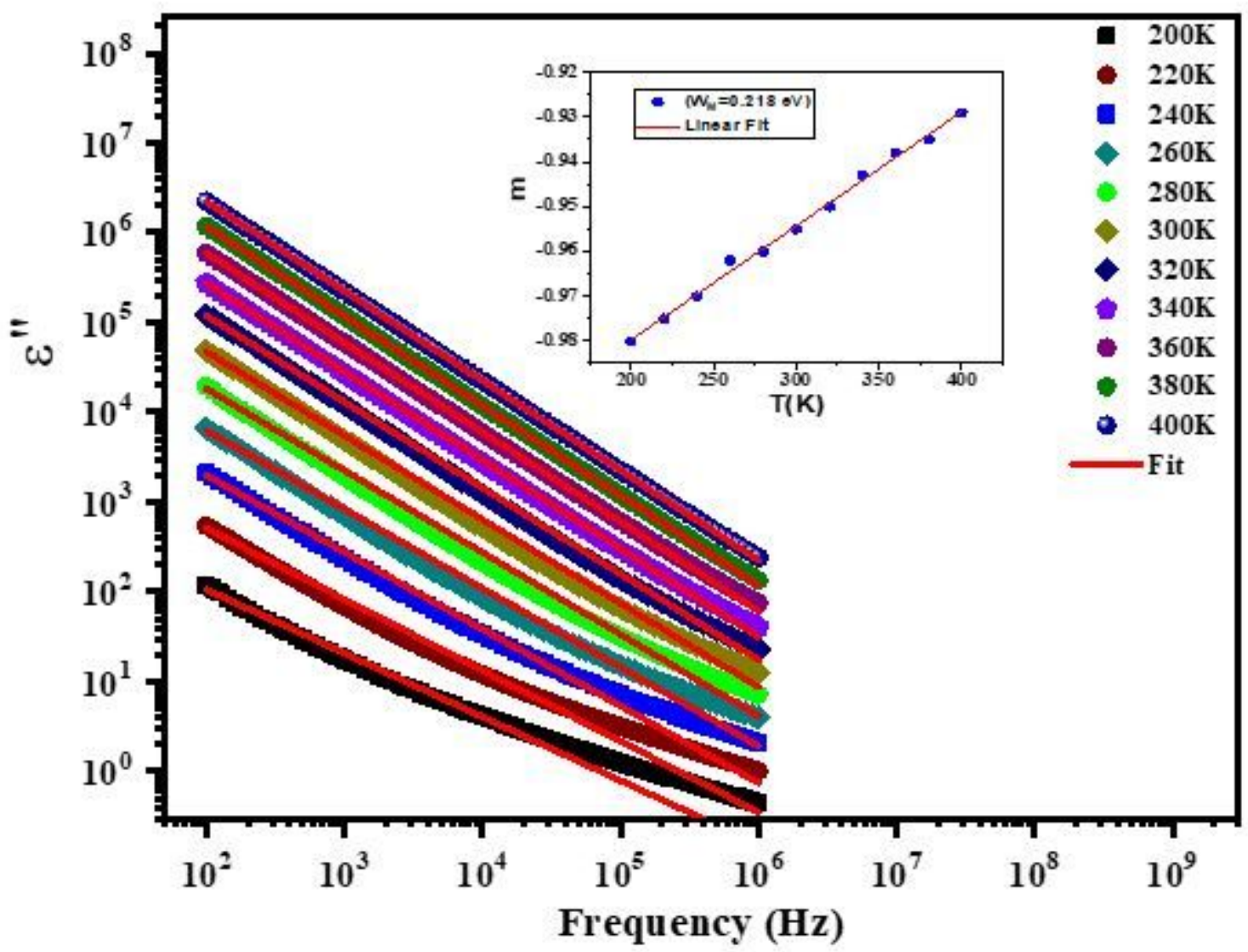

Figure 7

Frequency dependence at different temperatures of the imaginary part of permittivity for CuFeCr0.5Ni0.504. Red solid lines represent the fit according to Giuntini equation. The insets show the temperature dependence of the parameter $\mathrm{m}$. 


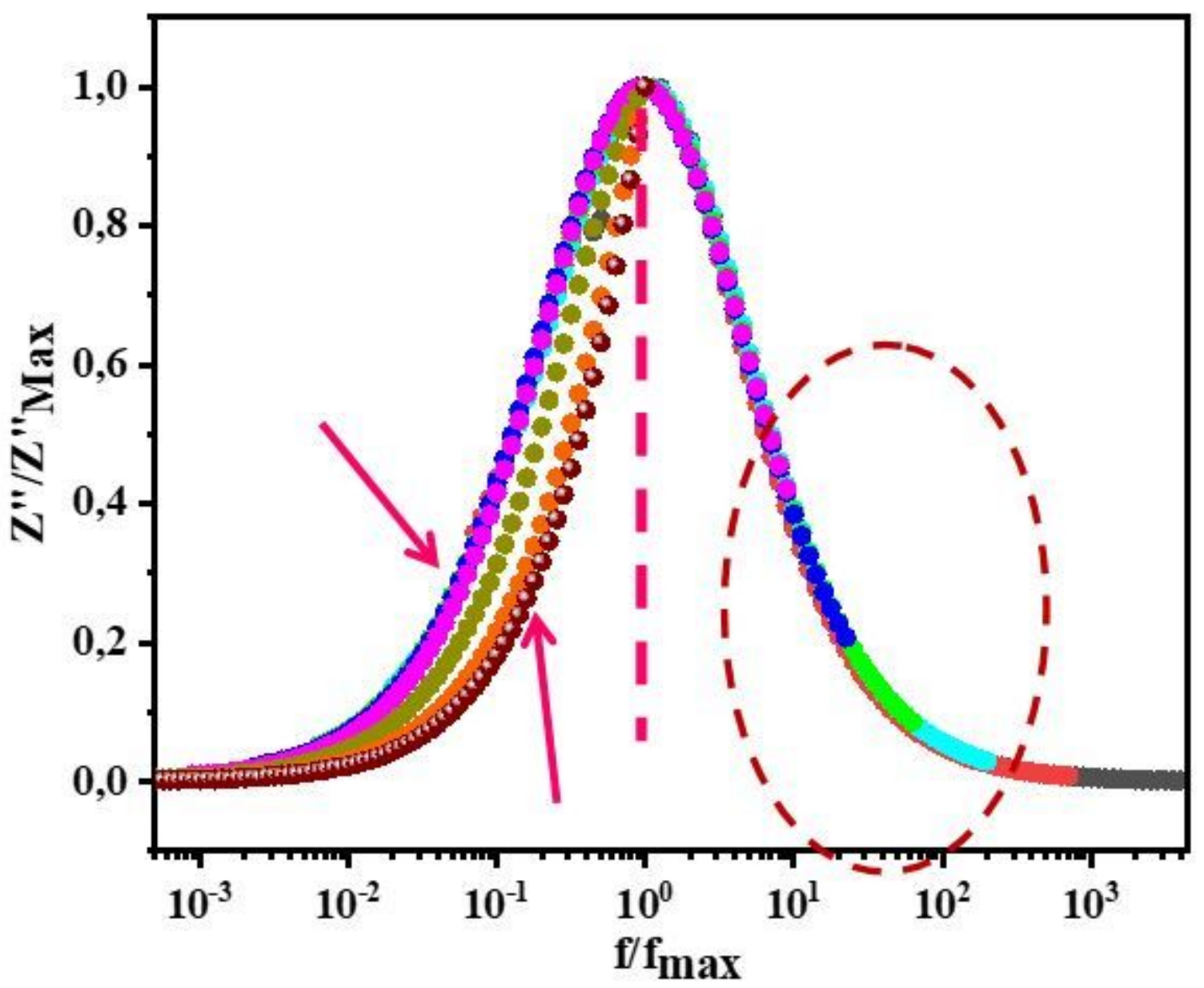

Figure 8

Scaling behavior of Z" curves at various temperatures for CuFeCr0.5Ni0.504.d ( 


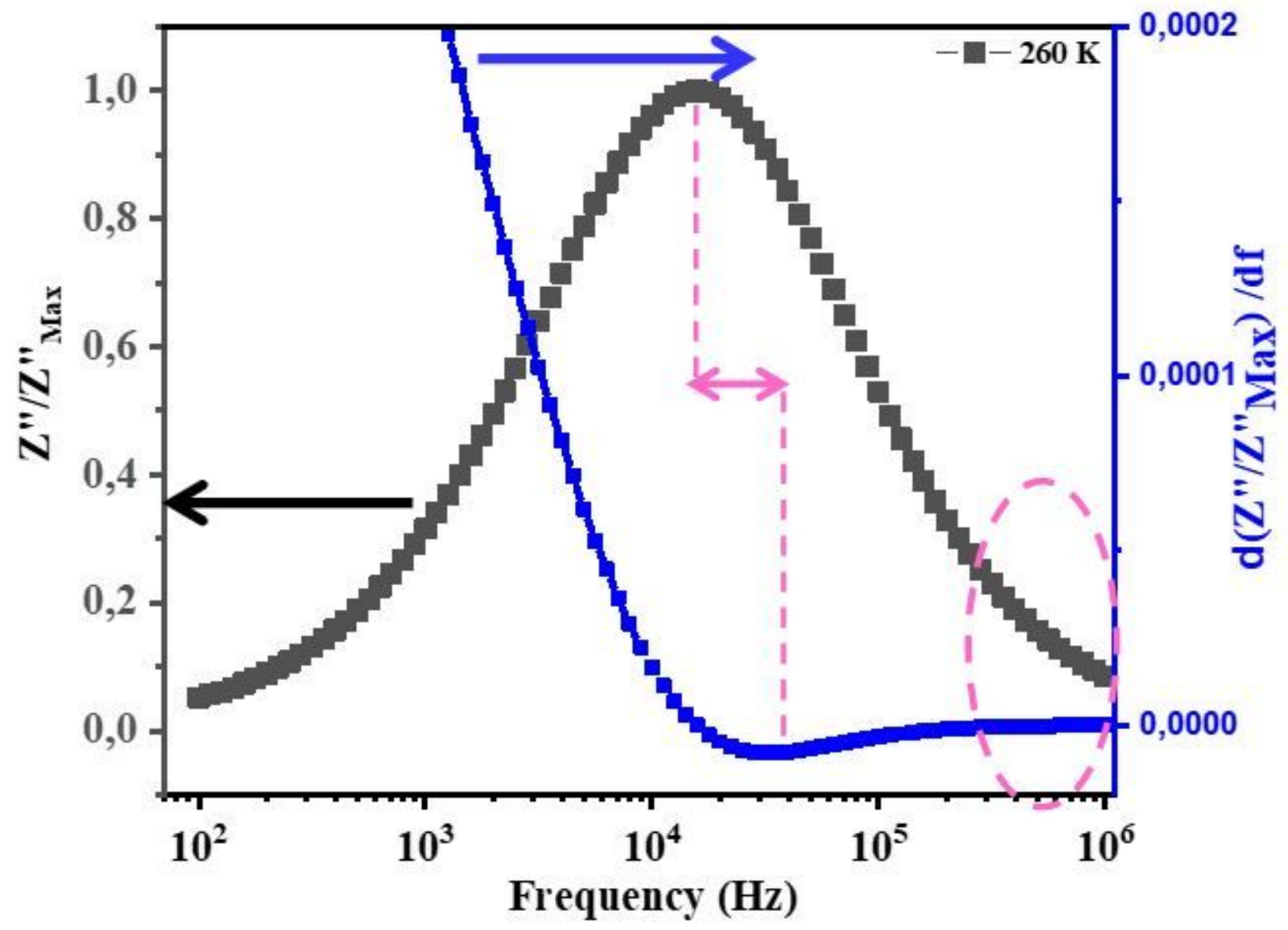

Figure 9

"Please see the Manuscript PDF file for the complete figure caption". 


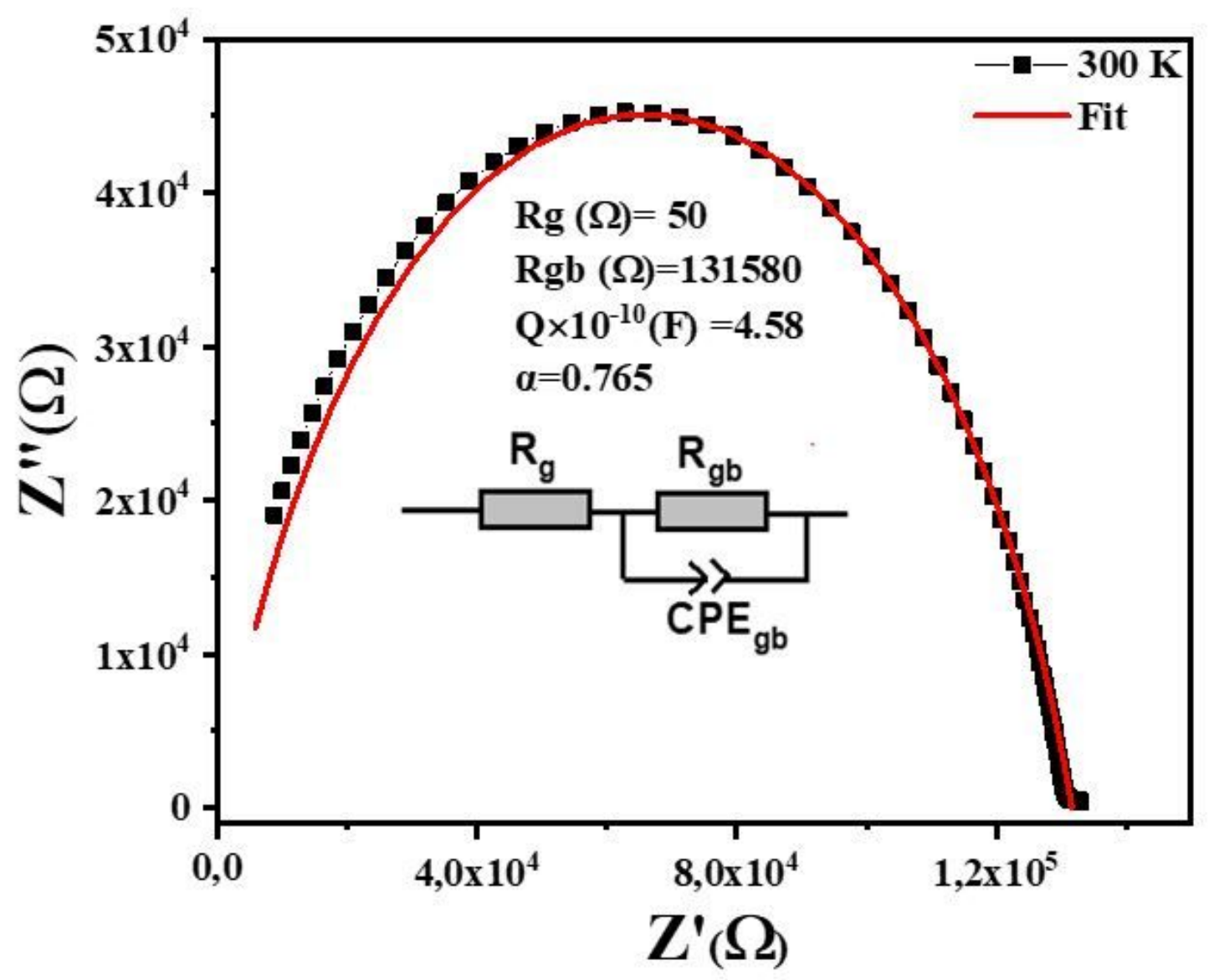

Figure 10

Complex impedance spectra for fitting using Zview software. Inset: the appropriate equivalent electrical circuit. 


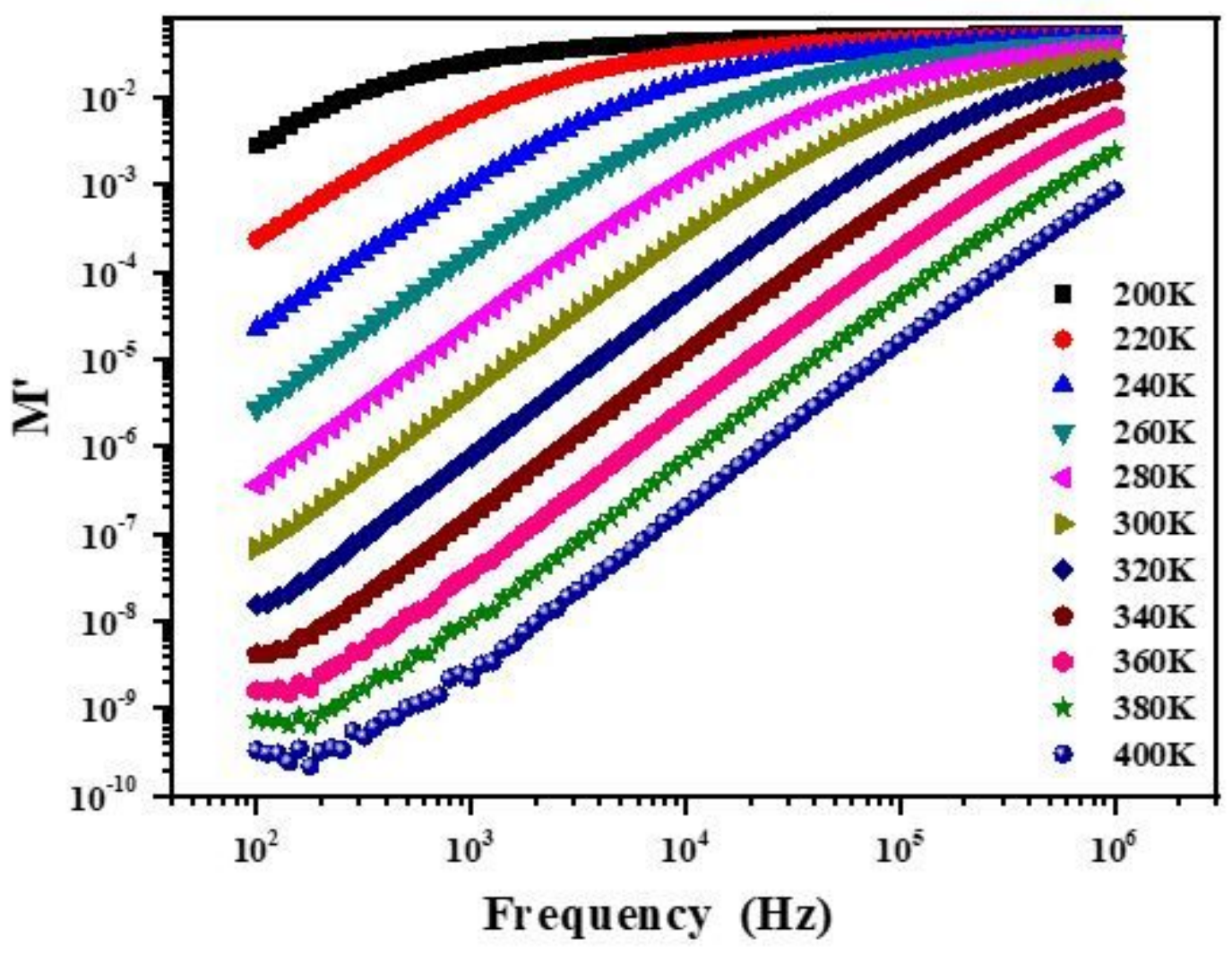

Figure 11

Frequency dependence at different temperatures of real part ( $M$ ') of electrical modulus for CuFeCr0.5Ni0.504. 


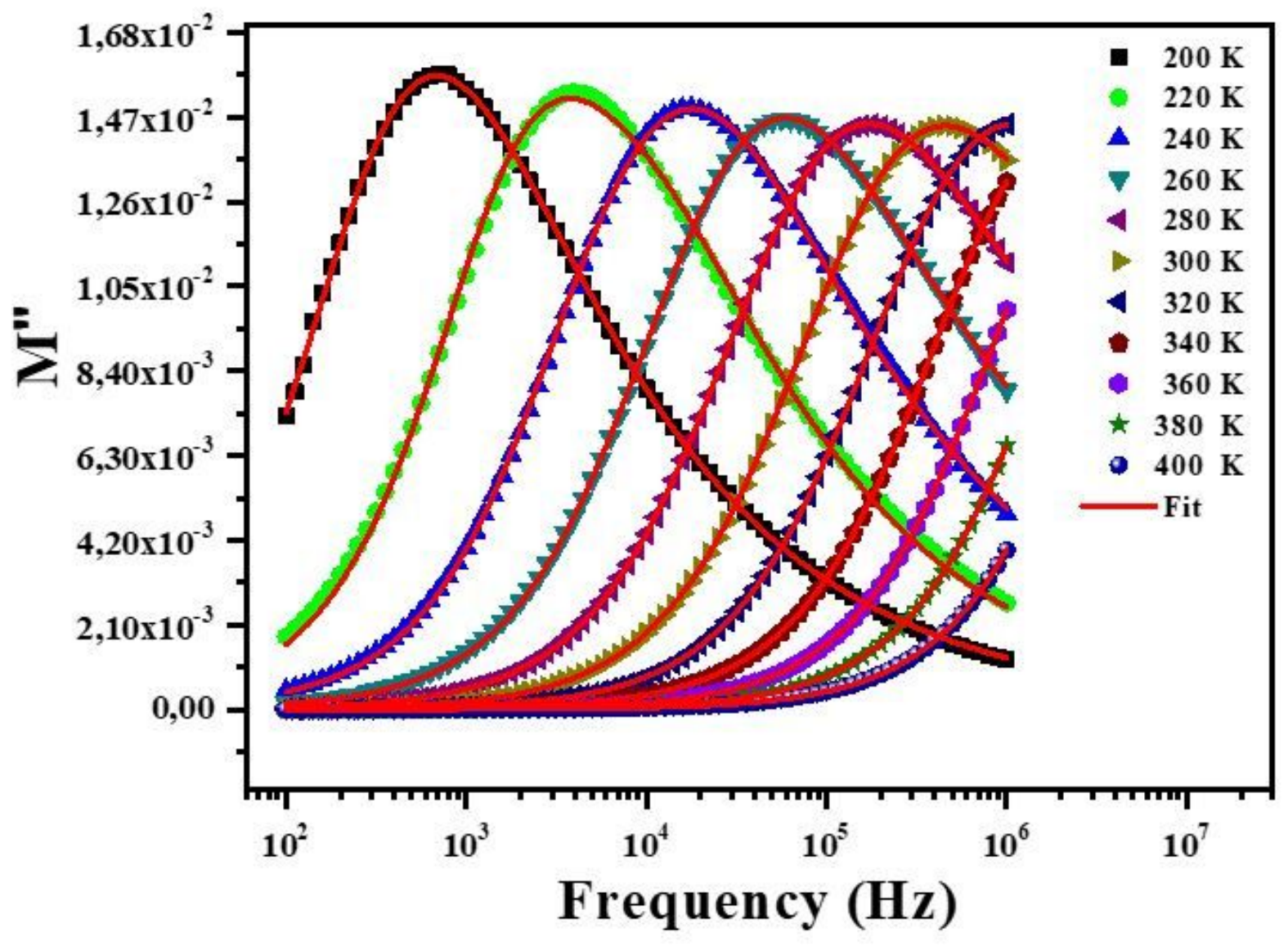

Figure 12

Frequency dependence at different temperatures of imaginary part (M") of electrical modulus for CuFeCr0.5Ni0.504. Red solid lines represent the fitting to the experimental data of M"(f) using KWW function 


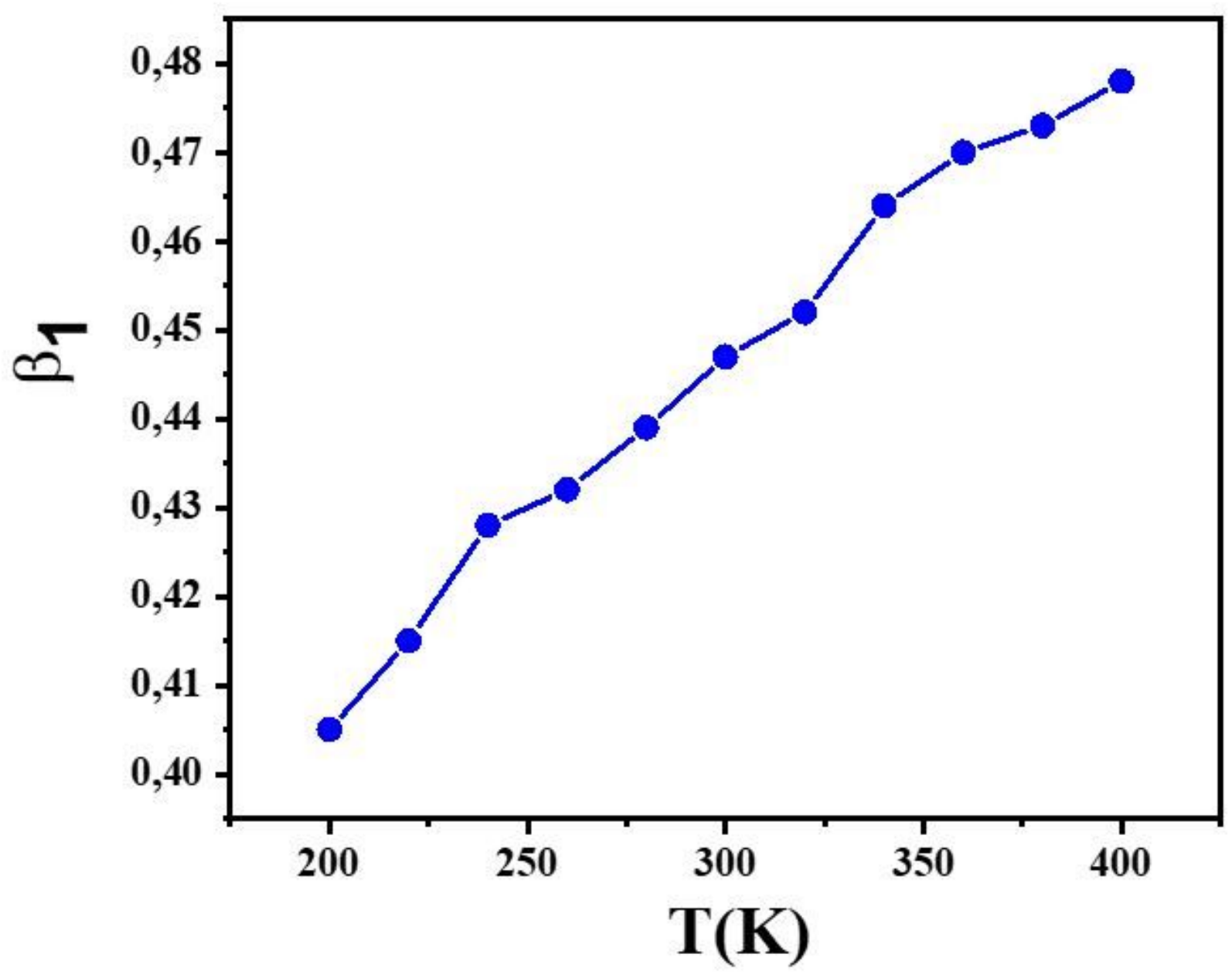

Figure 13

Variation of $\beta 1$ vs. temperature for $\mathrm{Cr} 0.5 \mathrm{Ni0} .5 \mathrm{FeCuO} 4$. 


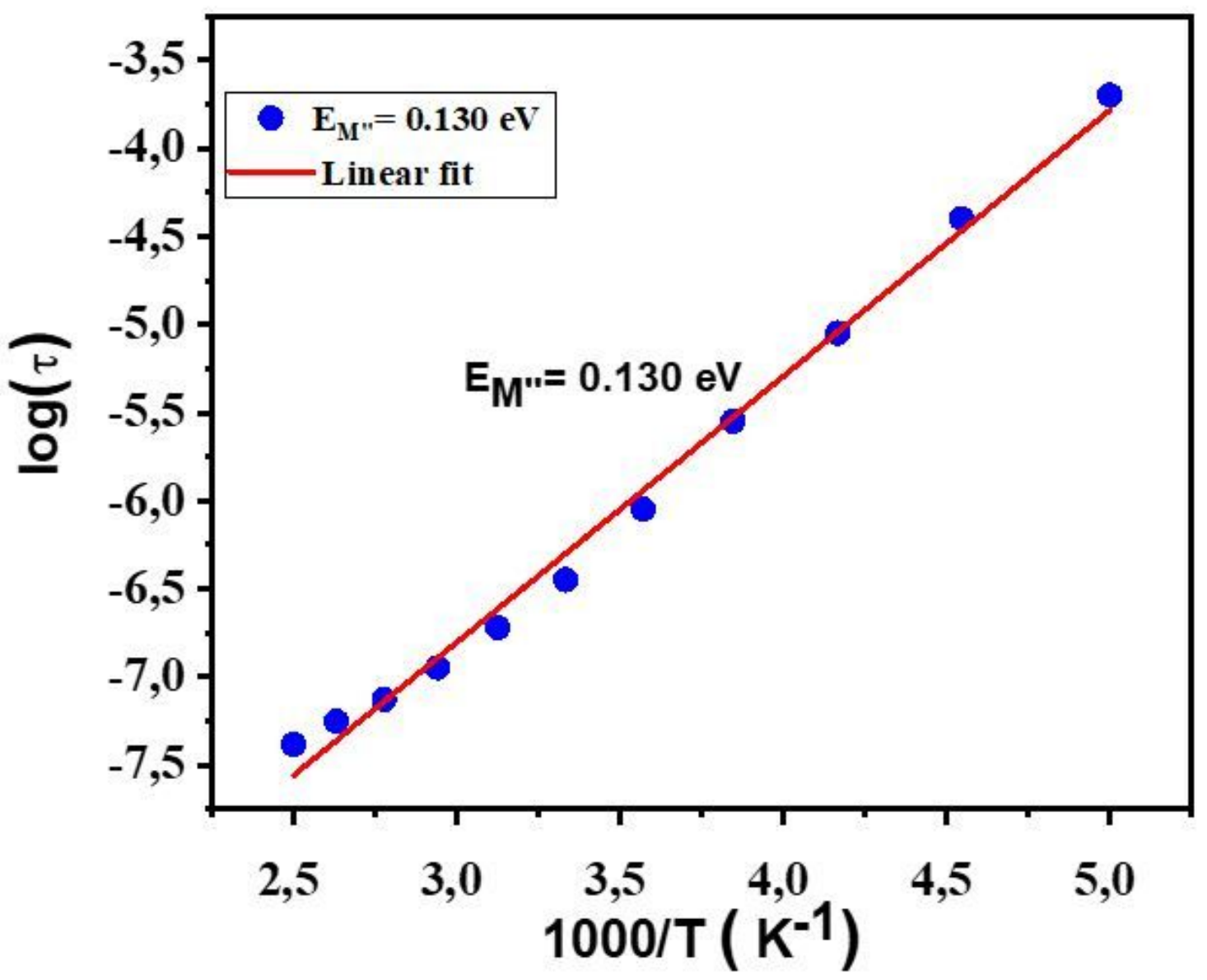

Figure 14

The $\log (\mathrm{TM} ")$ versus $(1000 / \mathrm{T})$. Red solid line is the linear fit for Cr0.5Ni0.5FeCuO4. 